\title{
A VEGETAÇÃO DA ESTAÇÃO ECOLÓGICA DE XITUÉ, RIBEIRÃO GRANDE-SP: SUBSÍDIOS PARA O PLANO DE MANEJO' ${ }^{1}$
}

\section{THE VEGETATION OF XITUÉ ECOLOGICAL STATION, SÃO PAULO STATE, BRAZIL: SUPPORT FOR ITS MANAGEMENT PLAN}

\author{
Flaviana Maluf SOUZA ${ }^{2,7}$; Roque CIELO-FILHO ${ }^{3}$; Natália Macedo IVANAUSKAS²; \\ Geraldo Antônio Daher Corrêa FRANCO ${ }^{2}$; Maria Teresa Zugliani TONIATO ${ }^{4}$; \\ Isabel Fernandes de Aguiar MATTOS ${ }^{5}$; Marina Mitsue KANASHIRO ${ }^{5}$; \\ Osny Tadeu AGUIAR ${ }^{6}$; João Batista BAITELLO ${ }^{6}$
}

\begin{abstract}
RESUMO - Este estudo teve como objetivo caracterizar a vegetação da Estação Ecológica de Xitué (EEcX), para subsidiar a elaboração do Plano de Manejo. A caracterização da vegetação foi feita com base em interpretação de fotografias aéreas e levantamento de campo, no qual foram observados atributos da estrutura da vegetação e a composição de espécies em trilhas com diferentes graus de conservação. Fez-se também um levantamento das pesquisas realizadas na EEcX e das coletas de espécies vegetais registradas nas coleções biológicas disponíveis on-line. A busca por dados secundários revelou a total ausência de estudos e coletas botânicas na Estação. A vegetação predominante na EEcX é a Floresta Ombrófila Densa Montana, que recobre $57,1 \%$ da área, seguida pela Floresta Ombrófila Aberta com Bambus $(41,3 \%)$. Há também pequenos trechos de Floresta Ombrófila Densa Alto-Montana (0,12\%), Floresta Ombrófila Densa Aluvial (1,2\%) e Vegetação Secundária $(0,17 \%)$. De modo geral, a vegetação apresenta porte médio e dossel irregular, com diversas manchas dominadas por bambus. Foram identificadas 123 espécies nativas, pertencentes a 82 gêneros e 40 famílias. Destas, nove constam em alguma categoria de ameaça nas listas de espécies ameaçadas no estado de São Paulo, no Brasil e no mundo. Não foram observadas espécies exóticas ou invasoras. A maior parte da área da $\operatorname{EEcX}(62,2 \%)$ foi considerada de extrema prioridade para conservação, sendo $37,7 \%$ de alta prioridade e $0,09 \%$ de média prioridade. Com base no grau de conservação, propõe-se, para o zoneamento, que $58 \%$ da EEcX seja destinada à zona primitiva, sendo o restante designado como zona de recuperação.
\end{abstract}

Palavras-chave: Floresta Ombrófila Densa; Mata Atlântica; bambus; Serra de Paranapiacaba; Avaliação Ecológica Rápida.

\begin{abstract}
The objective of this study was to characterize the vegetation of the Xitue Ecological Station (EEcX) in order to subsidize the elaboration of its Management Plan. The vegetation assessment was conducted based on a map generated by photointerpretation and field surveys, in which attributes of vegetation structure and species composition were recorded. Additionally, surveys on studies conducted in the EEcX, as well as on plant species recorded in biological collections available online were done. The search for secondary data revealed total absence of studies and botanical collections at the EEcX. The predominant vegetation in the Station is the Montane Ombrophilous Dense Forest, which covers $57.1 \%$ of the area, followed by the Ombrophilous Open Forest with Bamboos (41.3\%). There are also small areas of Upper Montane Ombrophilous Dense Forest (0.12\%), Alluvial Ombrophilous Dense Forest $(1.2 \%)$, and Secondary Vegetation $(0.17 \%)$. Overall, the overstory is mediumsized with irregular canopy, and several patches are dominated by bamboos. A total of 123 native species belonging to 82 genera and 40 families were identified. Nine out of these are
\end{abstract}

\footnotetext{
${ }^{1}$ Recebido para análise em 13.9.2013. Aceito para publicação em 10.9.2014.

${ }^{2}$ Instituto Florestal, Seção de Ecologia Florestal, Rua do Horto, 931, CEP 02377-000, São Paulo, SP, Brasil.

${ }^{3}$ Instituto Florestal, Floresta Estadual de Avaré, Rua Pernambuco, s/nº, CEP 18701-180, Avaré, SP, Brasil.

${ }^{4}$ Instituto Florestal, Estação Experimental de Bauru, Av. Rodrigues Alves, 38-25, CEP 17030-000, Bauru, SP, Brasil.

${ }^{5}$ Instituto Florestal, Seção de Introdução, Rua do Horto, 931, CEP 02377-000, São Paulo, SP, Brasil.

${ }^{6}$ Instituto Florestal, Seção de Madeiras e Produtos Florestais, Rua do Horto, 931, CEP 02377-000, São Paulo, SP, Brasil.

${ }^{7}$ Autor para correspondência: Flaviana Maluf Souza - flavianams@yahoo.com.br
} 
included the red lists of São Paulo State, Brazil and global. There were neither exotic nor invasive species on the trails assessed. Most of the EEcX (62.2\%) was considered of extreme importance for conservation, $37.7 \%$ of high importance, and $0.09 \%$ of medium importance. For the management plan, it is proposed that $58 \%$ of the $\mathrm{EEcX}$ be assigned to the primitive zone, and the remaining area be designated as recovery zone.

Keywords: Ombrophilous Dense Forest; Atlantic Forest; bamboos; Paranapiacaba Range; Rapid Ecological Assessment.

\section{INTRODUÇÃO}

Uma das áreas mais bem conservadas do que resta da Floresta Atlântica no Brasil é o Contínuo de Paranapiacaba, formado pela união do Parque Estadual Turístico do Alto Ribeira - PETAR, do Parque Estadual Carlos Botelho - PECB, do Parque Estadual Intervales - PEI e da Estação Ecológica de Xitué - EEcX. Com 120.000 ha, esse conjunto de Unidades de Conservação - UCs faz parte das sete grandes áreas contínuas de Floresta Atlântica identificadas por Ribeiro et al. (2009) no país.

A criação de áreas legalmente protegidas pelo poder público na forma de Unidades de Conservação é amplamente reconhecida como uma estratégia eficaz para a conservação in situ da biodiversidade de fauna e flora, e das interações entre ambas, bem como para a manutenção dos diversos serviços ambientais prestados, a conservação de valores históricos, arqueológicos e culturais, além do valor para manutenção do patrimônio natural em longo prazo e herança para as futuras gerações (Xavier et al., 2008; Araújo, 2012; Brasil, 2014).

No Brasil, a Lei 9.985/2000, que institui o Sistema Nacional de Unidades de Conservação - SNUC (Brasil, 2000), determina que as UCs disponham de um Plano de Manejo, definido como o documento técnico que estabelece o zoneamento e as normas que devem presidir o uso e o manejo dos recursos naturais da área, com base nos objetivos gerais de sua criação (Brasil, 2000). Portanto, o Plano de Manejo deve orientar a gestão do patrimônio contido nessas áreas protegidas, de forma que os propósitos a que estas se destinam sejam adequadamente cumpridos. No que diz respeito à conservação da biodiversidade, é fundamental que o Plano de Manejo seja técnica e cientificamente embasado, e contemple os diversos temas que envolvem o conhecimento da biota da área protegida. No caso da vegetação, a importância das avaliações técnico-científicas justifica-se, basicamente, pela necessidade de: a) reconhecer e mapear os diferentes tipos de vegetação existentes, a área ocupada por cada um e o seu estado de conservação; b) identificar as espécies da flora presentes, destacando-se as ameaçadas e as que devem ser alvo de manejo (por exemplo, as espécies exóticas); c) propor zoneamento que atenda às prioridades de conservação e às necessidades de manejo identificadas.

No contexto regional, ou seja, na porção sul do estado de São Paulo, a elaboração do Plano de Manejo da EEcX é de grande importância, visto que, assim, concluem-se os Planos de Manejo das UCs localizadas no Contínuo de Paranapiacaba. Isso possibilita a definição de uma proposta de gestão integrada dessas UCs, consolidando uma visão mais ampla da biodiversidade no Contínuo e permitindo aos gestores o estabelecimento de estratégias conjuntas para a conservação dessa importante região.

Este estudo teve como objetivo caracterizar a vegetação da Estação Ecológica de Xitué como parte das atividades integrantes do Módulo "Avaliação da Biodiversidade", que subsidiaram a elaboração do seu Plano de Manejo. Além das informações sobre aspectos gerais da vegetação, o estudo apresenta uma contribuição significativa para o conhecimento da flora dessa área pouco conhecida e de extremo interesse para a conservação da Floresta Atlântica. 


\section{MÉTODOS}

\section{1 Área de estudo}

A Estação Ecológica de Xitué está localizada no município de Ribeirão Grande, estado de São Paulo (2417’02"S; 48 19'55”W), na Serra de Paranapiacaba (Figura 1). Abrange uma área de 3.095 ha, em que predomina a Floresta Ombrófila Densa, de acordo com o sistema de classificação da vegetação brasileira (Instituto Brasileiro de Geografia e Estatística, 2012), em altitudes que vão de 759 a 1.020 m. A temperatura mínima no município de Ribeirão Grande é de $9,4^{\circ} \mathrm{C}$ e a máxima, de $29^{\circ} \mathrm{C}$ (Centro de Pesquisas Meteorológicas e Climáticas Aplicadas à Agricultura, 2014). A precipitação média anual varia de 1.400 a 1.600 mm (São Paulo, 1998).

Do ponto de vista geomorfológico, a EEcX está inserida no Planalto de Guapiara, apresentando como relevo predominante os morrotes baixos e serras paralelas (São Paulo, 1998). Na região, ocorrem Argissolos Vermelho-Amarelos, Cambissolos Háplicos, Latossolos Vermelhos e Vermelho-Amarelos, Gleissolos, Neossolos Litólicos, Neossolos Flúvicos e Organossolos (Oliveira et al., 1999).

$\mathrm{O}$ acesso à área é feito por estradas de servidão e, posteriormente, por trilhas que passam dentro de propriedades particulares. A EEcX possui apenas três trilhas e poucas vias de acesso.

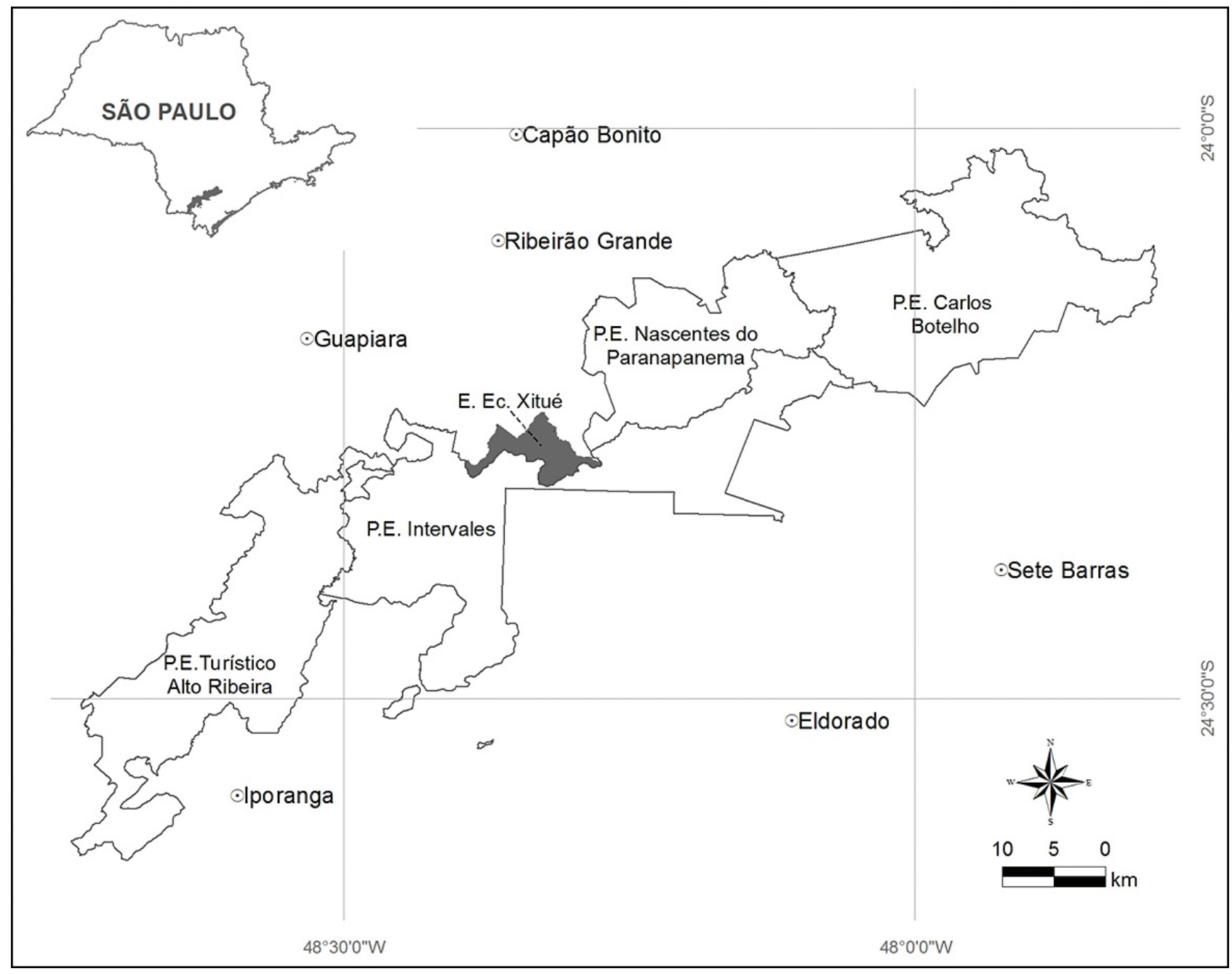

Figura 1. Localização da Estação Ecológica de Xitué, Ribeirão Grande-SP.

Figure 1. Location of the Xitué Ecological Station, municipality of Ribeirão Grande, São Paulo state, Brazil. 


\subsection{Mapeamento da cobertura vegetal}

O mapeamento da vegetação foi realizado por meio da fotointerpretação de fotografias aéreas verticais em colorido natural, na escala de 1:35.000, obtidas em 2001 pela AEROCARTA-BASE-ENGEFOTO para a SMA/SP-PPMA-KFW, e por mosaico aerofotogramétrico digital do mesmo voo. A fotointerpretação contou com auxílio de trabalhos de campo para a checagem das fisionomias mapeadas. As informações levantadas foram digitalizadas com o programa Arcview 3.2 e transportadas para a base cartográfica digital do Ribeirão Itacolomi e de Capão Bonito, do Instituto Brasileiro de Geografia e Estatística - IBGE, na escala 1:50.000.

O método básico de análise está centrado nos procedimentos adotados por Lueder (1959) e Spurr (1960), que identificam e classificam a vegetação utilizando elementos da imagem fotográfica, como cor, tonalidade, textura, forma, dimensão e convergência de evidências. A observação de outros atributos, como porte e densidade da vegetação, e uniformidade do dossel, complementou essa avaliação.

\subsection{Caracterização da vegetação}

Com o objetivo de reunir todas as informações disponíveis sobre a vegetação e utilizar esse conhecimento para orientar as propostas de conservação e manejo, fez-se um extenso trabalho de busca por dados provenientes de estudos desenvolvidos na EEcX. Este levantamento foi realizado por meio de consultas a publicações técnicas e científicas disponíveis nas bibliotecas das Universidades Estaduais (USP, UNESP e UNICAMP) e em bases de dados disponíveis na internet, como o SinBiota (www.sinbiota.org.br), Web of Science (www.periodicos. capes.gov.br), Scielo (www.scielo.org) e Google Acadêmico (www.scholar.google.com.br). Também foram consultados relatórios de projetos de pesquisa disponíveis no acervo da Comissão Técnico-Científica-COTEC, do Instituto Florestal do Estado de São Paulo. Com o objetivo de obter listas de espécies oriundas de pesquisas realizadas na EEcX, foram feitas consultas aos acervos dos herbários disponíveis on-line utilizando-se a base de dados SpeciesLink (http://splink.cria.org.br).

Além do levantamento de dados secundários, fez-se o levantamento da vegetação em campo. As trilhas percorridas foram selecionadas com base no mapa previamente elaborado (item 2.2) e em consultas feitas a funcionários da fiscalização e da área administrativa do Parque Estadual Intervales - PEI, a respeito do grau de conservação da vegetação. Dentre as três trilhas existentes, foram selecionadas as duas descritas como mais bem conservadas, que foram denominadas, para este estudo, "trilha de Xitué" e "trilha do Rio das Almas". A trilha de Xitué inicia-se no PEI, sendo necessário caminhar por aproximadamente $1,5 \mathrm{~km}$ até o limite entre as duas Unidades. Na trilha do Rio das Almas, o deslocamento a partir da sede do PEI demora cerca de uma hora e vinte minutos de carro, acrescida de cerca de uma hora de caminhada em propriedade particular, até que se chegue ao acampamento dos funcionários da fiscalização do PEI, onde se inicia a EEcX propriamente dita. Nessas trilhas, as divisas entre a EEcX e o PEI não apresentam demarcações físicas (marcos, placas etc.), sendo conhecidas somente pelos funcionários da fiscalização.

Para a caracterização da vegetação, foi aplicada uma adaptação do método proposto pela The Nature Conservancy - TNC, denominado “Avaliação Ecológica Rápida - AER” (Keel et al., 2003). A AER tem como um dos principais fundamentos a obtenção de dados biológicos em levantamentos expeditos realizados em campo e sua associação com imagens de sensoriamento remoto. Assim, informações sobre a vegetação e a distribuição das espécies são integradas, e podem ser visualizadas espacialmente, o que constitui uma ferramenta extremamente importante para o planejamento de ações de conservação em diferentes escalas (Keel et al., 2003).

Durante o levantamento, foram delimitados diferentes trechos das trilhas para a caracterização da vegetação. A definição dos trechos foi baseada em características que indicassem mudanças no grau de conservação em decorrência de alterações na fisionomia vegetal e na composição de espécies. Assim, cada trilha foi subdividida em um ou mais trechos, que foram georreferenciados com o auxílio de GPS. A caracterização fisionômica da vegetação teve como foco principal o componente arbóreo, sendo utilizados indicadores que permitissem uma análise do estádio sucessional da floresta (ex.: porte das árvores, densidade do subosque, estratificação da vegetação, presença de espécies exóticas e invasoras, entre outros - Anexo 1), estimados visualmente. Fez-se também o levantamento das espécies com ênfase nas plantas arbóreas nativas ao longo das 
trilhas. Espécies de outras formas de vida foram eventualmente registradas quando muito abundantes. Além das espécies nativas, foram observadas a presença e a distribuição de espécies exóticas, definidas como aquelas com ocorrência fora dos limites geográficos historicamente reconhecidos (Ziller, 2001). A avaliação foi feita por estimativa visual, atribuindo-se valores à presença e abundância destas espécies nos diferentes trechos das trilhas percorridas ( 0 - ausente; 1 - pouco abundante; 2 - muito abundante).

A coleta do material botânico foi realizada com o auxílio de uma tesoura de poda alta e as árvores de maior porte foram escaladas por profissional habilitado. O material foi posteriormente herborizado e, para a identificação, foi utilizada bibliografia especializada, comparação com exsicatas existentes em herbários ou ainda consulta a especialistas. Todo o material fértil foi incorporado ao Herbário Dom Bento Pickel (SPSF). A classificação das espécies em famílias, bem como grafia e a sinonimização, seguiram prioritariamente a Lista de Espécies da Flora do Brasil (http://floradobrasil.jbrj.gov.br/). Quando necessário, foram adicionalmente consultados os bancos de dados W3 Trópicos (http://mobot.mobot.org/W3T/Search/vast.html), International Plant Names Index (http://www.ipni.org/index.html) e The Plant List (http://www.theplantlist.org). As famílias e espécies foram organizadas segundo o sistema proposto pelo Angiosperm Phylogeny Group - APG (2009).

Após a finalização da identificação, verificou-se a ocorrência das espécies em alguma das categorias de ameaça definidas nas listas oficiais de espécies ameaçadas no estado de São Paulo (Mamede et al., 2007), no Brasil (Brasil, 2008) e no mundo (International Union for Conservation of Nature, 2013).

\subsection{Classificação dos trechos de acordo com o grau de conservação}

Os trechos delimitados em cada trilha foram classificados de acordo com o estado de conservação com base nas informações obtidas no levantamento de campo. Características fisionômicas, como a altura e o diâmetro das árvores do dossel, a estratificação, a densidade do subosque, a presença e a quantidade de bambus, taquaras, lianas e epífitas foram os principais atributos considerados. As categorias relativas ao grau de conservação seguiram o padrão já aplicado em outros planos de manejo (ex.: Instituto Florestal, 2008; Fundação Florestal, 2008, 2010), sendo definidas com base na ocorrência simultânea de algumas características da vegetação, a saber:

- Extremo: Presença de árvores no dossel com diâmetro à altura do peito (DAP) superior a $1 \mathrm{~m}$, subosque ralo e baixa ou nenhuma abundância de bambus e taquaras. Maior grau de conservação da vegetação quando comparada a outras áreas. Áreas com vocação para conservação e pesquisa;

- Alto: Predominância de árvores de grande porte no dossel $(20 \mathrm{~cm}<\mathrm{DAP} \leq 1 \mathrm{~m})$, subosque ralo e baixa ocorrência de bambus e taquaras. Vocação para a conservação, pesquisa e atividades educativas de impacto mínimo;

- Médio: Áreas com árvores de pequeno e médio porte (DAP $\leq 20 \mathrm{~cm})$ compondo o dossel ou áreas abertas com ocorrência de árvores esparsas, subosque com alta ou média densidade e bambus e taquaras abundantes. Vegetação em estádio médio de sucessão secundária.

- Baixo: Baixa riqueza de espécies nativas. Alto grau de perturbação e expressiva abundância de bambus, taquaras e espécies ruderais e/ou exóticas.

\subsection{Definição de áreas prioritárias para conservação e pesquisa}

Com base no georreferenciamento realizado em campo, as trilhas e os trechos amostrados foram espacializados de forma a possibilitar o cruzamento das informações sobre os tipos de vegetação determinados na fotointerpretação e o grau de conservação de cada trecho, identificado no levantamento de campo. Para os tipos vegetacionais não amostrados em campo, foram consideradas somente as características da vegetação obtidas por fotointerpretação. 
As áreas prioritárias para conservação foram definidas, sobretudo, com base no grau de conservação da vegetação, de modo que quanto maior o grau de conservação, mais alta a prioridade. Além disso, formações florestais com pequena extensão e que constituíam habitats únicos na EEcX também foram priorizadas.

Os principais critérios empregados na definição de áreas prioritárias para a pesquisa foram o grau de conservação, a amplitude geográfica e o grau de conhecimento sobre as formações vegetais. Assim, foram eleitas como prioritárias as regiões ou áreas com as seguintes características: i) cobertura vegetal representada por formações geograficamente restritas; ii) cobertura vegetal representada por formações amplamente distribuídas mas pouco estudadas, e alto grau de conservação; iii) cobertura vegetal com baixo grau de conservação e conhecimento sobre sua dinâmica.

\subsection{Zoneamento}

A proposta para o zoneamento da EEcX foi feita considerando-se as áreas prioritárias para conservação e a sua adequação às características de três zonas estabelecidas no roteiro metodológico do IBAMA(Galante et al., 2002), de acordo com as seguintes definições:

- Zona intangível: É aquela em que a primitividade da natureza permanece a mais preservada possível, não se tolerando quaisquer alterações humanas, representando o mais alto grau de preservação. Funciona como matriz de repovoamento de outras zonas onde já são permitidas atividades humanas regulamentadas. Esta zona é dedicada à proteção integral de ecossistemas e dos recursos genéticos, e ao monitoramento ambiental. O objetivo básico do manejo é a preservação, garantindo a evolução natural;

- Zona primitiva: É aquela em que tenha ocorrido pequena ou mínima intervenção humana, contendo espécies da flora e da fauna ou fenômenos naturais de grande valor científico. Deve possuir características de transição entre a Zona Intangível e a Zona de Uso Extensivo. O objetivo geral do manejo é a preservação do ambiente natural e, ao mesmo tempo, facilitar as atividades de pesquisa científica e educação ambiental, permitindo-se formas primitivas de recreação;

- Zona de recuperação: É aquela que contém áreas consideravelmente antropizadas. Trata-se de zona provisória que, uma vez restaurada, será incorporada novamente a uma das Zonas permanentes. As espécies exóticas introduzidas deverão ser removidas e a restauração deverá ser natural ou naturalmente induzida. O objetivo geral de manejo é deter a degradação dos recursos ou restaurar a área. Esta Zona permite uso público somente para a educação.

\section{RESULTADOS E DISCUSSÃO}

\subsection{Formações vegetais na EEcX}

A vegetação predominante na EEcX é a Floresta Ombrófila Densa Montana, que recobre 57,1\% da área, seguida pela Floresta Ombrófila Aberta com Bambus (41,3\%). Há também pequenos trechos de Floresta Ombrófila Densa Alto-Montana (0,12\%), Floresta Ombrófila Densa Aluvial $(1,2 \%)$ e Vegetação Secundária $(0,17 \%)$ (Figura 2).

As áreas classificadas por fotointerpretação como Floresta Ombrófila Densa Montana de porte alto (Ma) apresentam bom estado de conservação, embora se observe a presença de bambus (Guadua spp., Merostachys spp. e Chusquea spp.) em pequenas manchas, que não chegam a descaracterizar a floresta, que mantém o dossel alto e uniforme. Essas áreas se situam entre 400 e $1.000 \mathrm{~m}$ de altitude, no Planalto de Guapiara, ocupando aproximadamente 1.594 ha (53,8\% da área). As porções classificadas como Floresta Ombrófila Densa Montana de porte médio (Mmd) correspondem às florestas da crista da Serra de Paranapiacaba, situadas sobre solos mais rasos e em condições climáticas menos favoráveis, como baixas temperaturas, ventos e neblina. Essas 


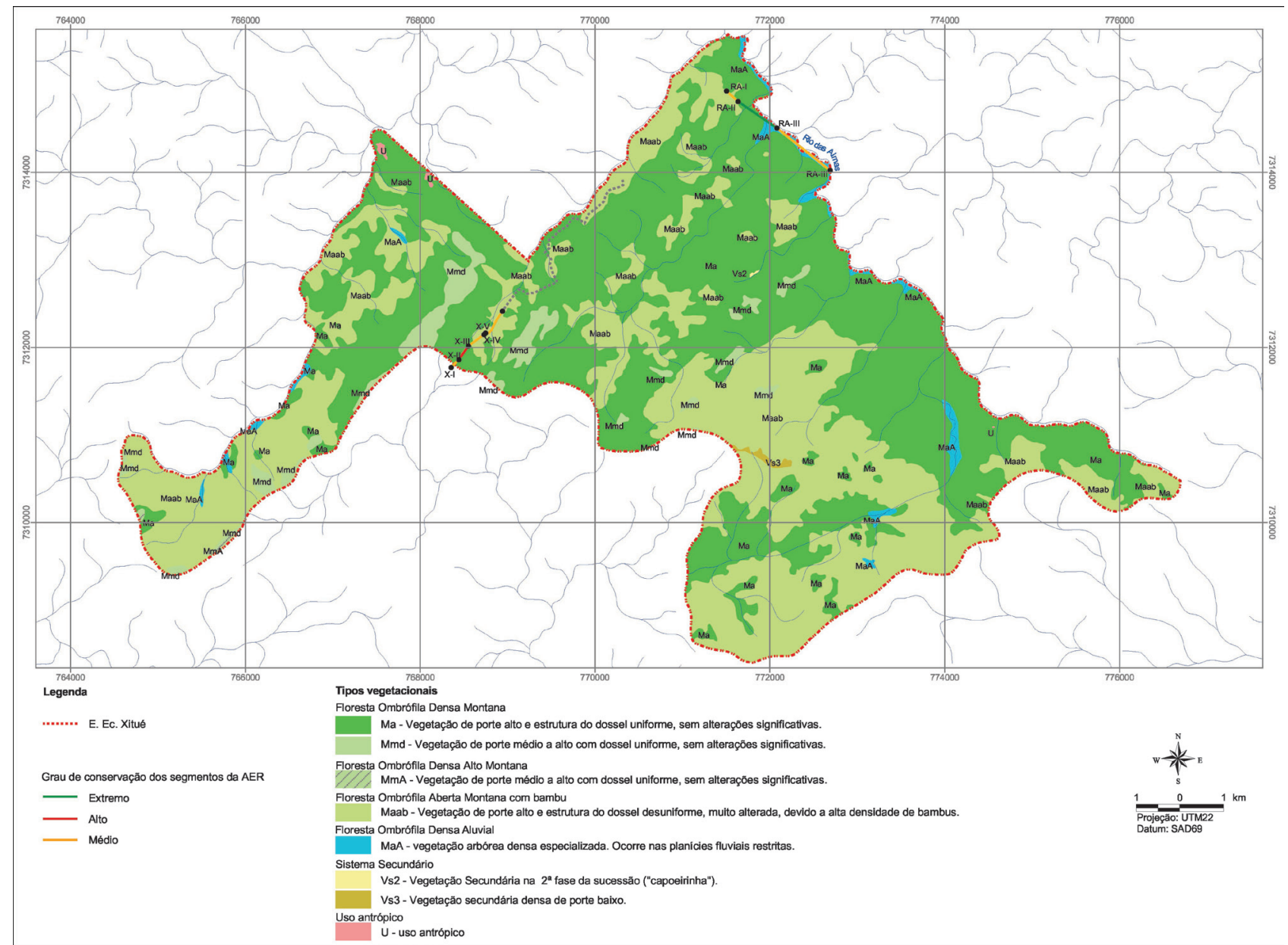

Figura 2. Cobertura vegetal e trilhas percorridas na Estação Ecológica de Xitué, Ribeirão Grande-SP.

Figure 2. Vegetation cover and trails used for the field survey at the Xitué Ecological Station, municipality of Ribeirão Grande, São Paulo state, Brazil.

manchas situam-se acima dos $900 \mathrm{~m}$ de altitude, nos topos dos interflúvios do Planalto de Guapiara e ocupam aproximadamente 98 ha (3,3\% da área). Seguindo-se a classificação do IBGE (2012), não é possível diferenciar as florestas que recobrem a vertente ocidental da Serra de Paranapiacaba daquelas que ocorrem na vertente oriental, ambas recebendo a denominação de Floresta Ombrófila Densa Montana. Contudo, à medida que se afasta do oceano e adentra-se o Planalto Atlântico, a Floresta Ombrófila Densa sofre influência progressivamente maior da Floresta Estacional Semidecidual e se diferencia floristicamente das florestas ombrófilas da vertente oriental. Este aspecto da vegetação é considerado no sistema de classificação de Eiten (1970), que atribui denominação própria para as florestas que recobrem a porção ocidental das Serras do Mar e de Paranapiacaba: a Floresta Sempre-Verde do Planalto e a Floresta da Crista da Serra do Mar. A influência da Floresta Estacional Semidecidual nessa região também já foi observada no Parque Estadual Intervales (São Paulo, 1998).

Duas manchas de vegetação, também de porte médio, as quais somam 3,5 ha e estão situadas a sudoeste, foram destacadas por estarem acima dos $1.000 \mathrm{~m}$ de altitude, tendo sido denominadas de Floresta Ombrófila Densa Alto-Montana (MmA). A fisionomia dessa vegetação identificada pela fotointerpretação é bastante semelhante à da Floresta Ombrófila Densa Montana de porte médio (Mmd), mas não foi possível caracterizá-la em campo pela impossibilidade de acesso à área.

Duas grandes porções foram denominadas de Floresta Ombrófila Aberta Montana com Bambu (Maab) e ocupam aproximadamente $1.225 \mathrm{ha}$, o que corresponde a uma parcela significativa $(41,3 \%)$ da EEcX. Nessas áreas, a vegetação encontra-se bastante alterada e com aparente impacto negativo dos bambus sobre 
o estabelecimento de outras espécies. Diferentes espécies de bambus nativos recobrem extensas áreas onde apenas algumas espécies arbóreas, sobretudo as pioneiras, ocorrem na forma de indivíduos isolados. Durante o levantamento, verificou-se a mortalidade em massa dos bambus após a frutificação. Nessas populações, os colmos encontravam-se prostrados, em processo de decomposição e cobertos por trepadeiras, formando um denso emaranhado. Essa condição provavelmente afeta a chegada de sementes e de luz ao solo e, consequentemente, dificulta a regeneração natural. Diversos autores já apontaram que os bambus podem, de fato, restringir a regeneração de espécies arbóreas (Oliveira-Filho et al., 1994; Carvalho, 1997; Widmer, 1998; Guilherme et al., 2004). Estudos realizados no Parque Estadual Carlos Botelho, situado no Contínuo Ecológico de Paranapiacaba, também mostraram a ocorrência de menor densidade de indivíduos e de espécies arbóreas em áreas dominadas por bambus. Os autores sugerem que a limitação da dispersão e a incidência de eventos de estresse sobre as plântulas - como excesso de radiação solar e elevadas temperaturas no subosque - seriam alguns dos fatores responsáveis pelos padrões observados (Rother et al., 2009; Lima et al., 2012). A dinâmica populacional dos bambus e o impacto sobre as demais espécies nativas merecem atenção especial no planejamento das ações de conservação e manejo da EEcX. Contudo, deve-se levar em conta que as fotografias aéreas utilizadas no presente diagnóstico foram tiradas em 2000/2001 e, portanto, é possível que as manchas tenham se alterado (expandido ou retraído). Desse modo, não se sabe o quanto a situação atual da área da EEcX corresponde ao que foi visto e interpretado nas fotos, e uma nova análise com base em fotos mais recentes é necessária para orientar a tomada de decisões.

A Floresta Ombrófila Densa Aluvial (MaA) apresentou padrão diferente das demais, ocupando pequenos trechos dispersos na paisagem, em uma área total de 36 ha. Tais áreas estavam situadas em planícies fluviais restritas e provavelmente estão sujeitas a inundações periódicas. O difícil acesso a estes locais não permitiu a checagem da fisionomia em campo.

Além das formações primárias, duas áreas foram definidas como vegetação secundária (Vs2 e Vs3). A Vs2, com 0,37 ha, situada a NE da EEcX, é uma antiga área de uso e apresenta vegetação em segunda fase do estádio sucessional, também chamada de "capoeirinha" (IBGE, 2012). Já a mancha Vs3 ocupa 4,7 ha e parece ser resultante da ocupação de bambus que, depois de morrerem, formaram uma grande clareira. Nessa área, não foi possível identificar, pela fotointerpretação, qual a forma de vida predominante, mas supõe-se que sejam trepadeiras que proliferaram após a morte dos bambus. Esta é também uma área que não foi verificada em campo por causa do difícil acesso.

\subsection{Caracterização da vegetação}

\subsubsection{Dados secundários}

As buscas às fontes de dados bibliográficos revelaram a total ausência de pesquisas sobre a vegetação da EEcX. Do mesmo modo, não foram encontrados registros de coletas de espécies vegetais em nenhuma das bases consultadas. Portanto, pode-se dizer que o grau de conhecimento sobre a vegetação da EEcX é nulo. Essa ausência de trabalhos contrasta fortemente com a quantidade de trabalhos desenvolvidos no Parque Estadual Intervales (Baider et al., 2001; Guilherme et al., 2004; Zipparro et al., 2005), que é contíguo à EEcX. Provavelmente, isso ocorre devido a questões logísticas que dificultam a realização de pesquisas na EEcX em comparação ao PEI. Dentre os principais fatores, destacam-se:

- O pequeno número de trilhas, sobretudo nas áreas mais bem conservadas;

- A dificuldade no acesso às trilhas existentes devido à distância e à necessidade de transitar por áreas particulares antes de se chegar à Estação;

- A falta de uma sede e de funcionários próprios, tanto para a realização de contatos e obtenção de informações sobre a Estação quanto para o acompanhamento das atividades de campo;

- Ausência de alojamentos e espaços para a acomodação de pesquisadores e equipamentos. 


\subsubsection{Aspectos gerais da vegetação nas trilhas percorridas}

Na trilha de Xitué, a vegetação caracteriza-se pela alternância de trechos, cujo principal componente que distingue a fisionomia é a abundância de bambus e taquaras (Anexo 1). Os trechos mais bem preservados (X-II e X-IV) podem ser classificados como Floresta Ombrófila Densa Montana, correspondendo a aproximadamente $24 \%$ do percurso realizado e ocorrendo próximos aos cursos d'água, nas áreas mais baixas da vertente. Nesses trechos, a estrutura da floresta é bastante estratificada, com clara diferenciação de dossel, subdossel e subosque. As árvores emergentes chegam a $20 \mathrm{~m}$ de altura e o dossel varia ao redor de $15 \mathrm{~m}$. Predominam árvores com diâmetro à altura do peito (DAP) entre $20 \mathrm{~cm}$ e $1 \mathrm{~m}$, e o subosque é ralo. A presença de epífitas é conspícua e os bambus e taquaras, embora presentes, não são abundantes.

Os trechos com predomínio de bambus situados na área de Floresta Ombrófila Aberta com Bambus (trechos X-I, X-III e X-V) são mais expressivos e correspondem a 76\% da porção percorrida da trilha. Nesses locais, a vegetação não apresenta dossel contínuo, sendo composta predominantemente por árvores isoladas. Com a mortalidade dos bambus, houve intensa proliferação de lianas agressivas, particularmente do gênero Mikania (Asteraceae), o que contribuiu para formar um subosque denso e com pouca regeneração de espécies arbóreas. Com base no mapa da cobertura vegetal (Figura 2), observou-se que a porção percorrida da trilha de Xitué correspondeu justamente à parte de floresta dominada por bambus. Nesse mapa, logo em seguida ao trecho amostrado, existem áreas aparentemente mais bem preservadas, mas que logo voltam a ser ocupadas pelas formações abertas com bambus.

Na trilha do Rio das Almas, observou-se situação bastante semelhante à da trilha de Xitué, com relação à fisionomia da vegetação. Percorreu-se aproximadamente $1,5 \mathrm{~km}$ dessa trilha ao longo do Rio das Almas, cruzando também o Rio Jacutinga. A trilha foi dividida em três trechos, sendo o primeiro (RA-I) e o último (RA-III) semelhantes entre si e distintos do segundo (RA-II) (Anexo 1). Esses dois trechos somam $64,2 \%$ do caminho percorrido e são ocupados pela Floresta Ombrófila Aberta com Bambus. As árvores possuem altura em torno de $15 \mathrm{~m}$, há poucas epífitas e o subosque tem média densidade, com baixa abundância de plantas herbáceas. Entre esses dois trechos, encontra-se novamente a vegetação classificada como Floresta Ombrófila Densa Montana. Nesta área, a floresta é mais preservada, apresentando maior porte e estratificação, com árvores emergentes com altura em torno de $20 \mathrm{~m}$, dossel ao redor de $16 \mathrm{~m}$ e árvores com DAP superior a $1 \mathrm{~m}$ (Anexo 1). Epífitas são abundantes e o subosque é ralo, composto de poucos bambus e muitas plantas herbáceas pertencentes às famílias Marantaceae e Heliconiaceae. Esse conjunto de características indica que esse trecho encontra-se em um estádio sucessional próximo ao da floresta madura.

\subsubsection{Composição florística e estrutura da vegetação}

O levantamento realizado na trilha de Xitué resultou no registro de 123 espécies arbustivas e arbóreas, distribuídas em 82 gêneros e 40 famílias (Tabela 1). Na trilha do Rio das Almas, foi realizada apenas a caracterização fisionômica da vegetação. Não foram constatadas espécies exóticas invasoras em nenhuma das trilhas percorridas.

A maior parte das espécies amostradas pode ser considerada típica da Floresta Ombrófila Densa. No estrato superior, destacam-se Chionanthus filiformis, Chrysophyllum viride, Copaifera trapezifolia, Micropholis crassipedicelata e Pouteria psammophila. No subdossel e subosque, foram observadas as espécies Bathysa australis, Cinnamodendron dinisii, Guatteria australis, Psychotria suterella e Rudgea jasminoides, entre outras. Também foram encontradas espécies frequentes na Floresta Estacional Semidecidual, como Cupania vernalis, Esenbeckia grandiflora e Schefflera morototoni. A presença de espécies da Floresta Estacional é comum em determinadas regiões do Contínuo Ecológico de Paranapiacaba, consideradas áreas de transição (ecótonos) entre a Floresta Ombrófila Densa e a Floresta Estacional Semidecidual (Fundação Florestal, 2008). Por se tratar de uma área ecotonal, em tese, a diversidade encontrada na EEcX é provavelmente ainda maior do que o verificado em outros trechos de Floresta Ombrófila Densa. Pesquisas sobre a flora em UCs no Domínio da Floresta Atlântica 


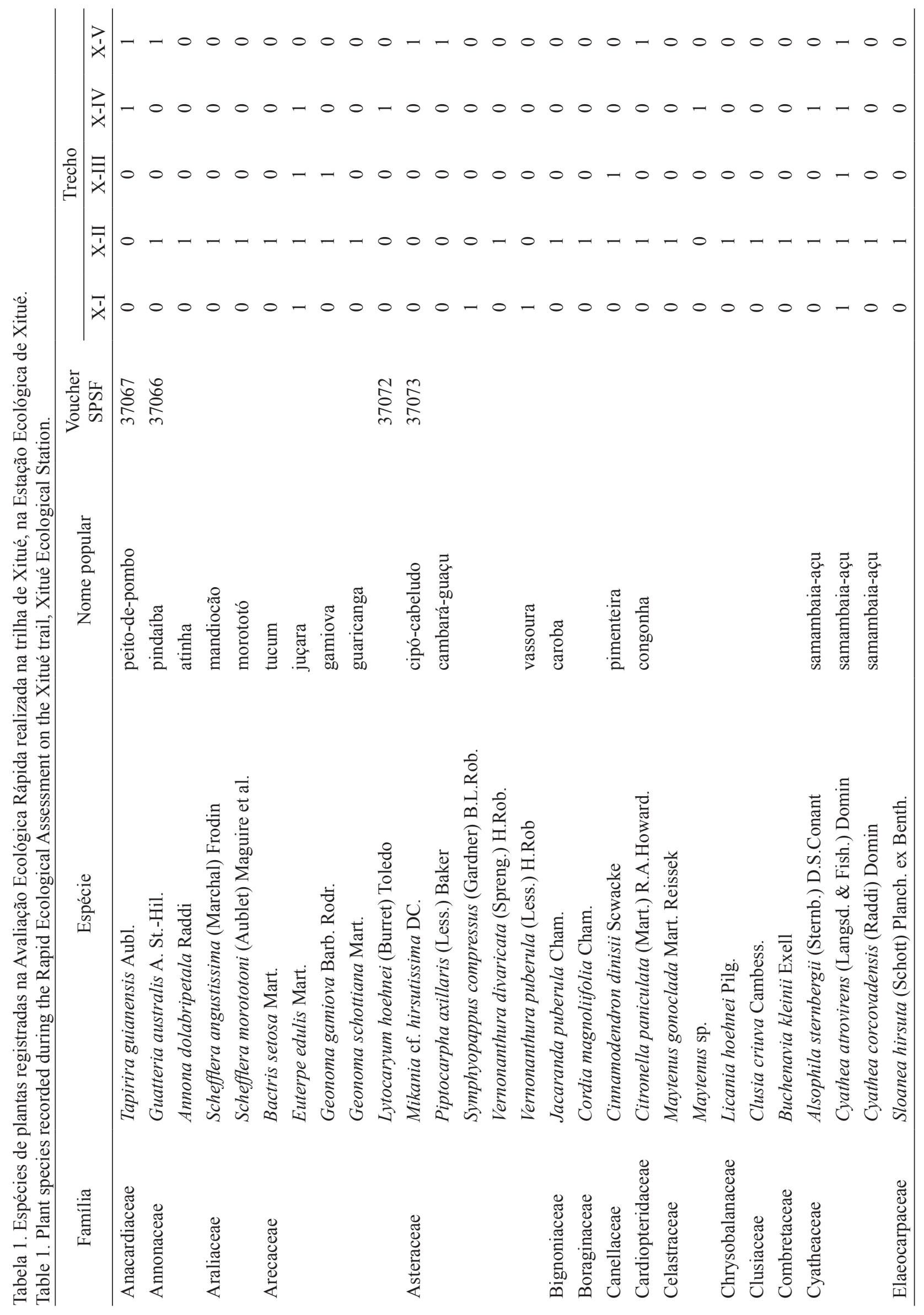


SOUZA, F. M. et al. A vegetação da Estação Ecológica de Xitué, Ribeirão Grande-SP: subsídios para o Plano de Manejo

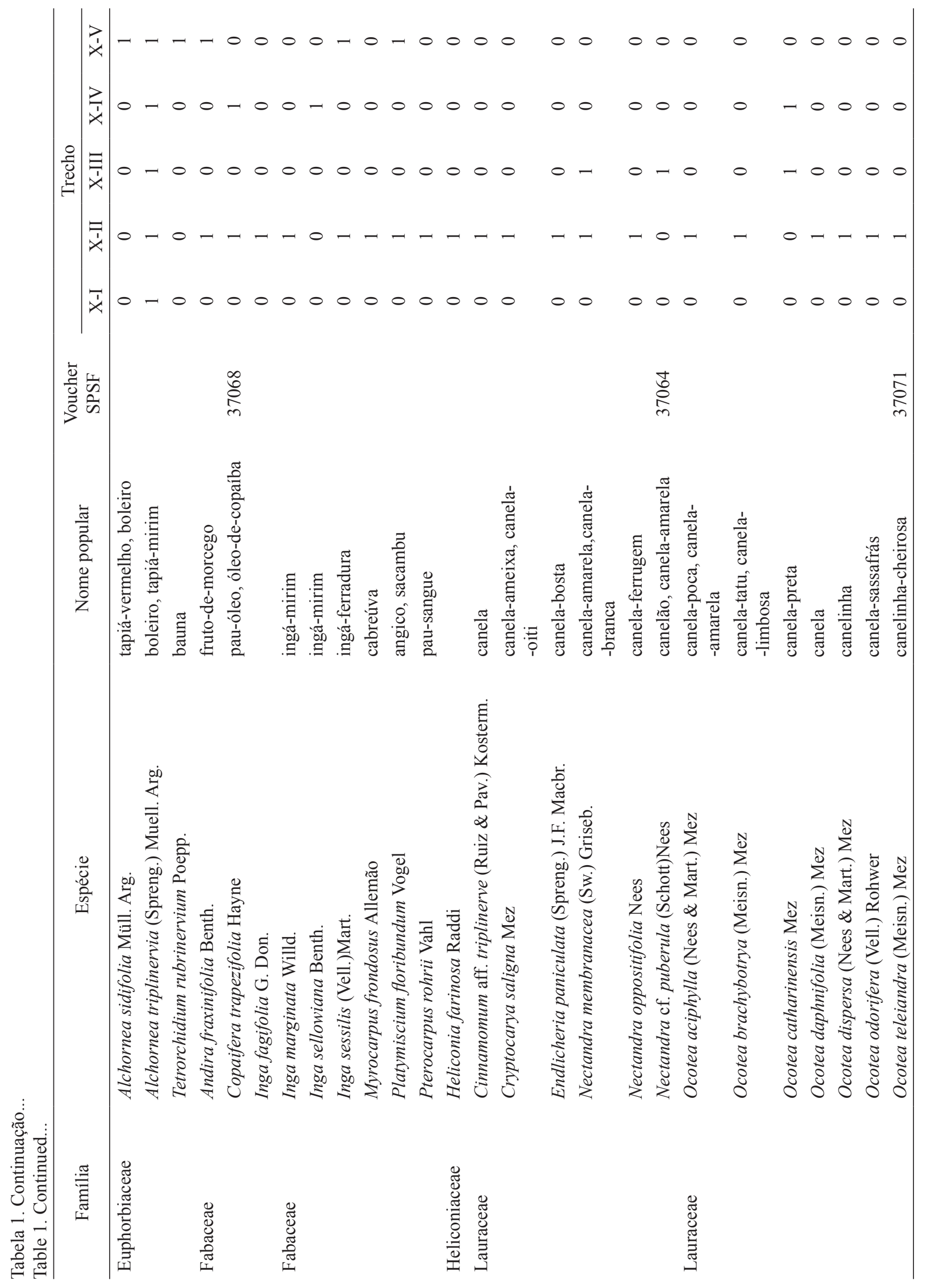




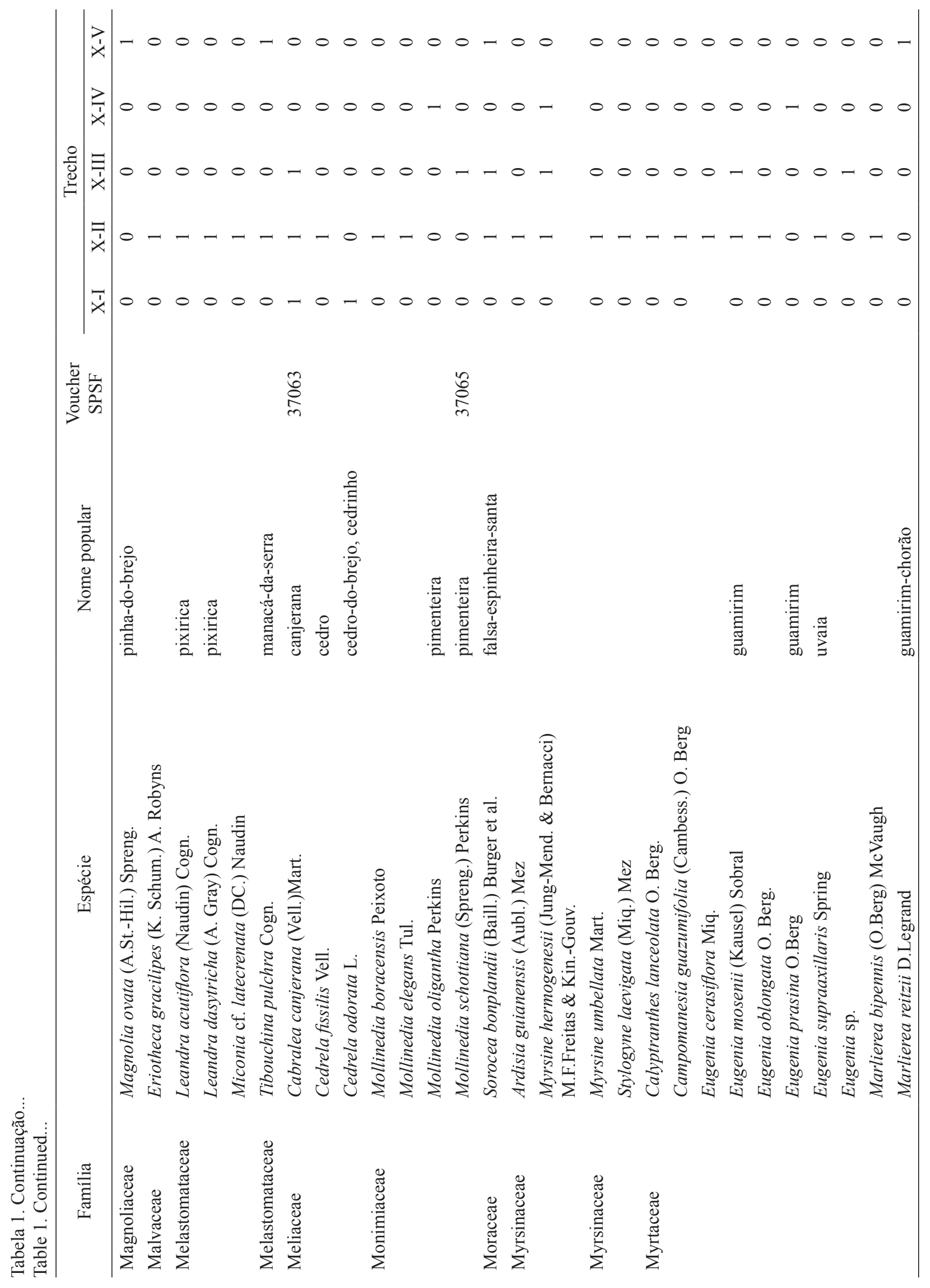


SOUZA, F. M. et al. A vegetação da Estação Ecológica de Xitué, Ribeirão Grande-SP: subsídios para o Plano de Manejo

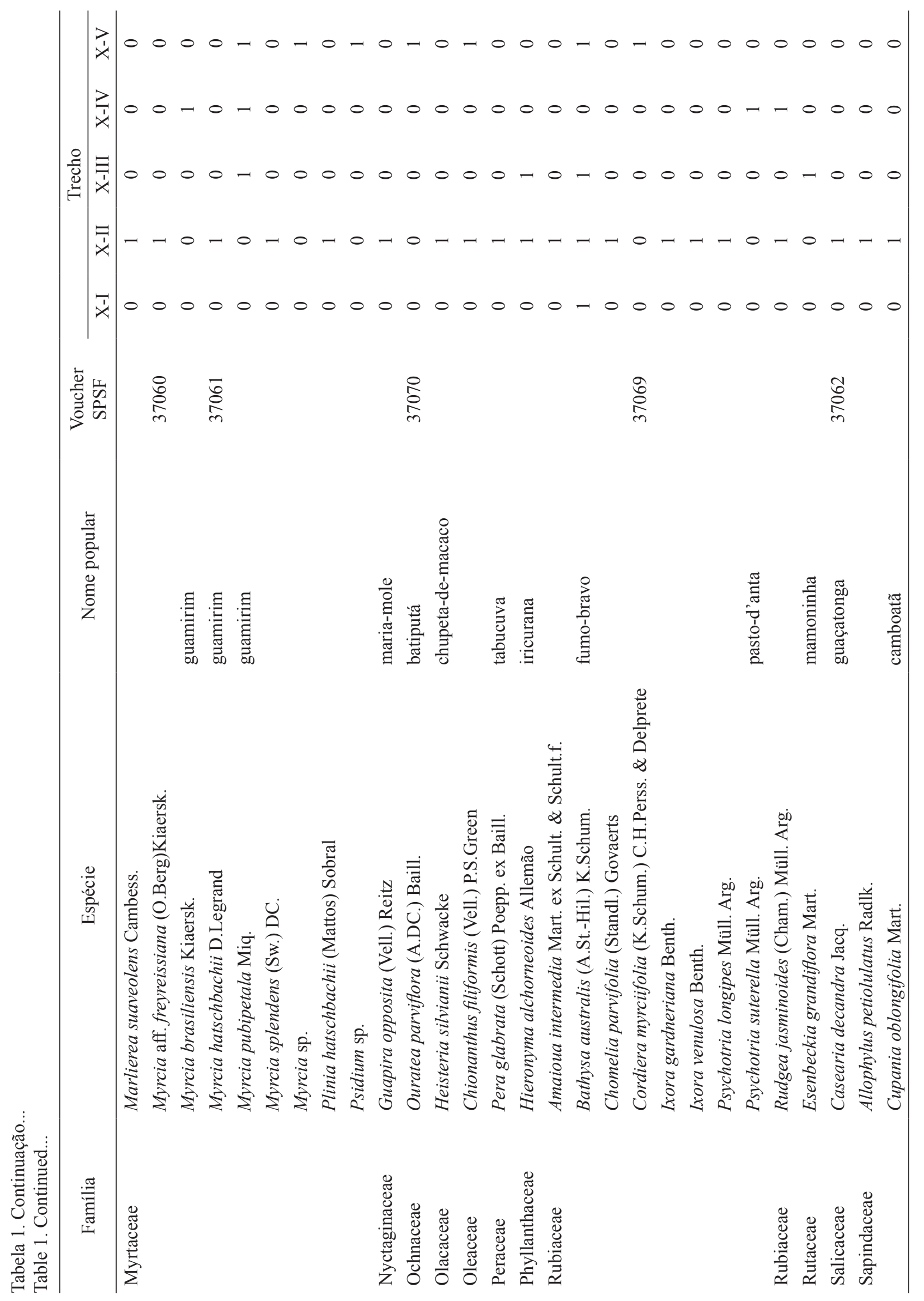




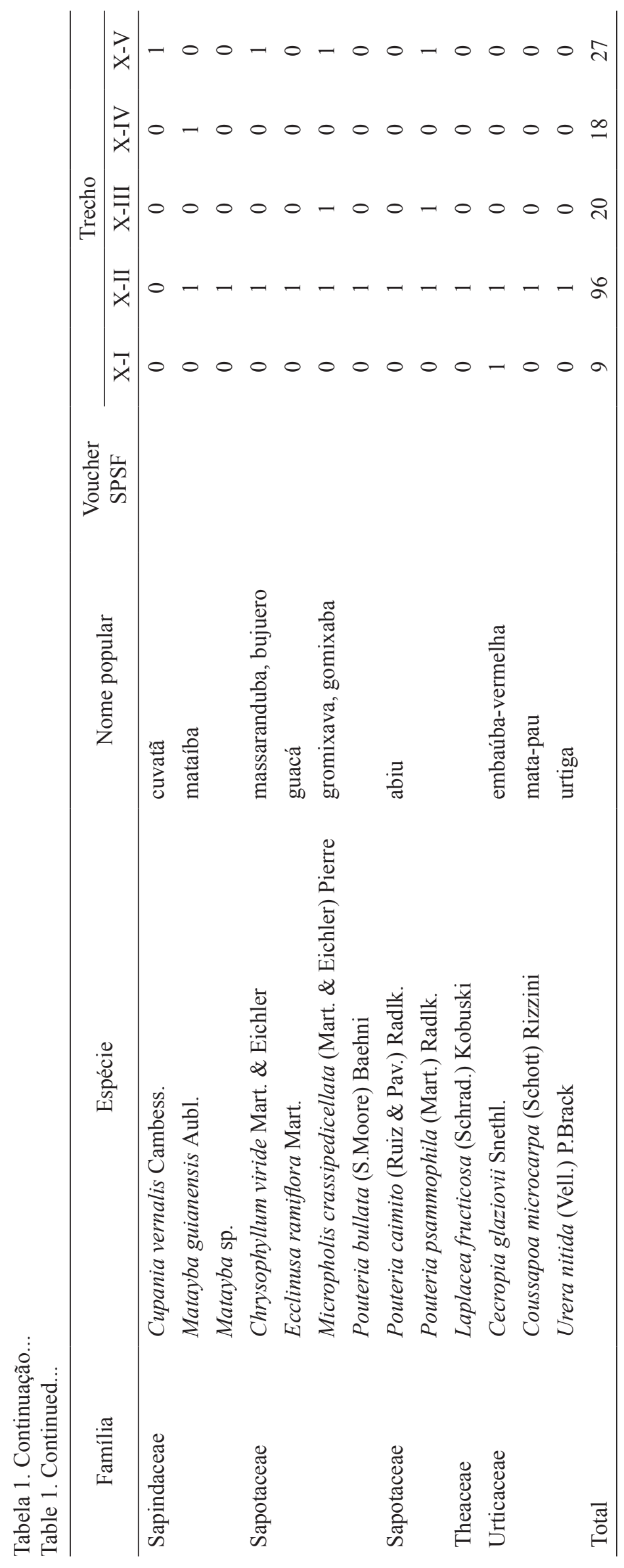


SOUZA, F. M. et al. A vegetação da Estação Ecológica de Xitué, Ribeirão Grande-SP: subsídios para o Plano de Manejo

têm revelado centenas de espécies ocorrendo em áreas relativamente pequenas (Thomas et al., 1998; Amorim et al., 2009; Cielo-Filho et al., 2009; Saiter et al., 2011; Rossetto e Vieira, 2013). Essa grande diversidade de espécies arbóreas observada em florestas tropicais decorre dos padrões de distribuição de abundância verificados nessas florestas. Em geral, observa-se elevada frequência de espécies raras e notável escassez de espécies muito abundantes quando comparadas às florestas temperadas (Hubbell, 1997, 2001; Leigh Junior et al., 2004).

Essa alta diversidade limita a determinação da riqueza total de espécies em levantamentos expeditos, mesmo para pequenas áreas. $\mathrm{O}$ mesmo se aplica, e com maior propriedade, para as espécies ameaçadas de extinção. Por essa razão, optou-se por classificar e comparar os trechos das trilhas somente pela fisionomia, a qual, por sua vez, também apresenta grande valor para inferências sobre diversidade e conservação. Em geral, observa-se notável correlação positiva entre o porte e a complexidade estrutural da vegetação e a riqueza de espécies de plantas em florestas tropicais (Tabanez e Viana, 2000). Assim, a análise da fisionomia, aliada à fotointerpretação, representa importante ferramenta para a avaliação da vegetação quanto ao estado de conservação e à necessidade de manejo.

Apesar das limitações do levantamento de campo e da ausência de dados secundários sobre coletas botânicas, nove espécies registradas na EEcX se enquadram em alguma das categorias de ameaça listadas pela Secretaria do Meio Ambiente do Estado de São Paulo, pelo Ministério do Meio Ambiente e pela União Internacional para a Conservação da Natureza (Tabela 2). Dentre estas, Marlierea suaveolens e Ocotea daphnifolia são consideradas vulneráveis no estado de São Paulo. Por sua vez, Euterpe edulis é considerada vulnerável no estado de São Paulo e também é citada na lista brasileira de espécies ameaçadas, provavelmente devido aos processos de intensa exploração comercial ao longo de décadas. Ocotea catharinensis consta tanto na lista brasileira quanto na lista mundial. Outras cinco espécies fazem parte somente da lista de espécies ameaçadas globalmente. Cedrela odorata e Pouteria bullata estão na categoria vulnerável, possivelmente devido à destruição de seu habitat natural e ao corte seletivo de árvores, motivado pelo valor comercial da madeira. Cedrela fissilis, Inga sellowiana e Pouteria psammophila encontram-se em perigo de extinção provavelmente pelo declínio populacional relacionado à degradação e à fragmentação de seus habitats.

Tabela 2. Espécies amostradas na trilha de Xitué, na Estação Ecológica de Xitué, enquadradas em alguma categoria de ameaça segundo as listas oficiais de espécies ameaçadas: SMA - Secretaria do Meio Ambiente do Estado de São Paulo; MMA - Ministério do Meio Ambiente; IUCN - União Internacional para a Conservação da Natureza.

Table 2. Species recorded on the Xitué trail, Xitué Ecological Station, included in the official red lists of São Paulo State; São Paulo State Department of Environment - SMA; Brazilian Environmental Ministry - MMA, and International Union for the Conservation of Nature - IUCN.

\begin{tabular}{llcc}
\hline \multicolumn{1}{c}{ Família } & \multicolumn{1}{c}{ Espécie } & Lista & Categoria \\
\hline Arecaceae & Euterpe edulis Mart. & SMA/MMA & Vulnerável \\
Fabaceae & Inga sellowiana Benth. & IUCN & Em perigo \\
Lauraceae & Ocotea catharinensis Mez & MMA/IUCN & Vulnerável \\
& Ocotea daphnifolia (Meisn.) Mez & SMA & Em perigo \\
Meliaceae & Cedrela fissilis Vell. & IUCN & Em perigo \\
& Cedrela odorata L. & IUCN & Vulnerável \\
Myrtaceae & Marlierea suaveolens Cambess. & SMA & Vulnerável \\
Sapotaceae & Pouteria bullata (S.Moore) Baehni & IUCN & Vulnerável \\
& Pouteria psammophila (Mart.) Radlk. & IUCN & Em perigo \\
\hline
\end{tabular}

É interessante notar que muitas dessas espécies foram encontradas nos trechos em que a vegetação encontra-se mais degradada, o que ressalta a importância de se protegerem também as áreas com menor grau de conservação (FRANCO et al., 2007). 
Além das espécies ameaçadas, o registro da palmeira Lytocaryum hoehnei fornece uma informação importante sobre sua distribuição. Apesar de não constar nas listas oficiais, há citações de que a espécie seja "rara", "ameaçada de extinção", e que seja endêmica da região metropolitana da cidade de São Paulo (Lorenzi et al., 1996). Em consulta à base de dados SpeciesLink, foram encontrados apenas 14 registros de coletas dessa espécie. Desse total, nove são do município de São Paulo, um do município de Cotia, um do município de Ibiúna, dois do município de Capão Bonito e um único registro no estado do Paraná, no município de Adrianópolis.

\subsection{Classificação dos trechos de acordo com o grau de conservação}

Conforme os critérios estabelecidos para a classificação da vegetação de acordo com o grau de conservação, apenas um dos trechos amostrados (localizado na trilha do Rio das Almas) foi considerado de extremo grau de conservação. Nessa trilha, os dois outros trechos foram considerados de médio grau, assim como três trechos da trilha de Xitué. Na trilha de Xitué, os dois trechos restantes foram classificados como de alto grau de conservação (Tabela 3).

Tabela 3. Localização geográfica (UTM/SAD69), número de espécies e grau de conservação da vegetação dos trechos amostrados na Estação Ecológica de Xitué. Lat - latitude; Long - longitude; Alt - altitude.

Table 3. Geographic location (UTM/SAD69), number of species and conservation status of vegetation in the trails sampled at the Xitué Ecological Station. Lat - latitude; Long - longitude; Alt - altitude.

\begin{tabular}{clcccccccc}
\hline \multirow{2}{*}{ Trilha } & \multirow{2}{*}{ Trecho } & \multirow{2}{*}{ Lat } & \multirow{2}{*}{ Long } & \multirow{2}{*}{$\begin{array}{l}\text { Alt } \\
(\mathrm{m})\end{array}$} & & \multicolumn{5}{c}{ Número de espécies* } & Grau de \\
Xitué & X-I & 7311769 & 768352 & 866 & 09 & 1 & 1 & 1 & Médio \\
& X-II & 7311859 & 768442 & 849 & 95 & 3 & 1 & 3 & Alto \\
& X-III & 7312014 & 768550 & 822 & 20 & 1 & 2 & 2 & Médio \\
& X-IV & 7312146 & 768727 & 831 & 18 & 1 & 2 & 2 & Alto \\
& X-V & 7312163 & 768744 & 831 & 27 & 0 & 0 & 1 & Médio \\
Rio das & RA-I & 7312414 & 768940 & 830 & - & & - & - & Médio \\
Almas** & RA-II & 7314930 & 771503 & 752 & - & - & - & - & Extremo \\
& RA-III & 7314807 & 771636 & 738 & - & - & - & - & Médio \\
\hline
\end{tabular}

* Espécies enquadradas em alguma categoria de ameaça segundo as listas da Secretaria do Meio Ambiente do Estado de São Paulo (SMA), do Ministério do Meio Ambiente (MMA) e da União Internacional para a Conservação da Natureza (IUCN).

** Nesta trilha, não foi realizada a caracterização florística.

Em decorrência do pequeno esforço amostral, a riqueza de espécies e o número de espécies enquadradas em alguma categoria de ameaça não foram utilizados para definir o grau de conservação, uma vez que esses atributos estão diretamente relacionados à extensão dos trechos e ao esforço de coleta (Magurran, 2004).

Considerando-se a distância total percorrida em ambas as trilhas, observou-se o predomínio de vegetação em grau médio de conservação, o que correspondeu a mais de $60 \%$ de cada percurso. Na trilha do Rio das Almas, a extensão do trecho mais bem conservado foi pouco maior que o trecho mais bem conservado da trilha de Xitué. Curiosamente, a presença dos bambus não foi exclusiva dos trechos com menor grau de conservação. Mesmo nas áreas mais bem preservadas (grau "alto" e "extremo") foram observados bambus, porém em menor densidade, não aparentando interferir negativamente na regeneração da floresta. 


\section{4 Áreas prioritárias para conservação e pesquisa}

A maior parte da $\operatorname{EEcX}(62,2 \%)$ foi considerada de extrema prioridade para conservação. Áreas com alta prioridade totalizaram $37,71 \%$ e o restante $(0,09 \%)$ foi considerado de média prioridade (Figura 3 ). As áreas consideradas de extrema e alta prioridade para conservação correspondem às fitofisionomias de Floresta Ombrófila Densa Alto-Montana, Montana e Aluvial.

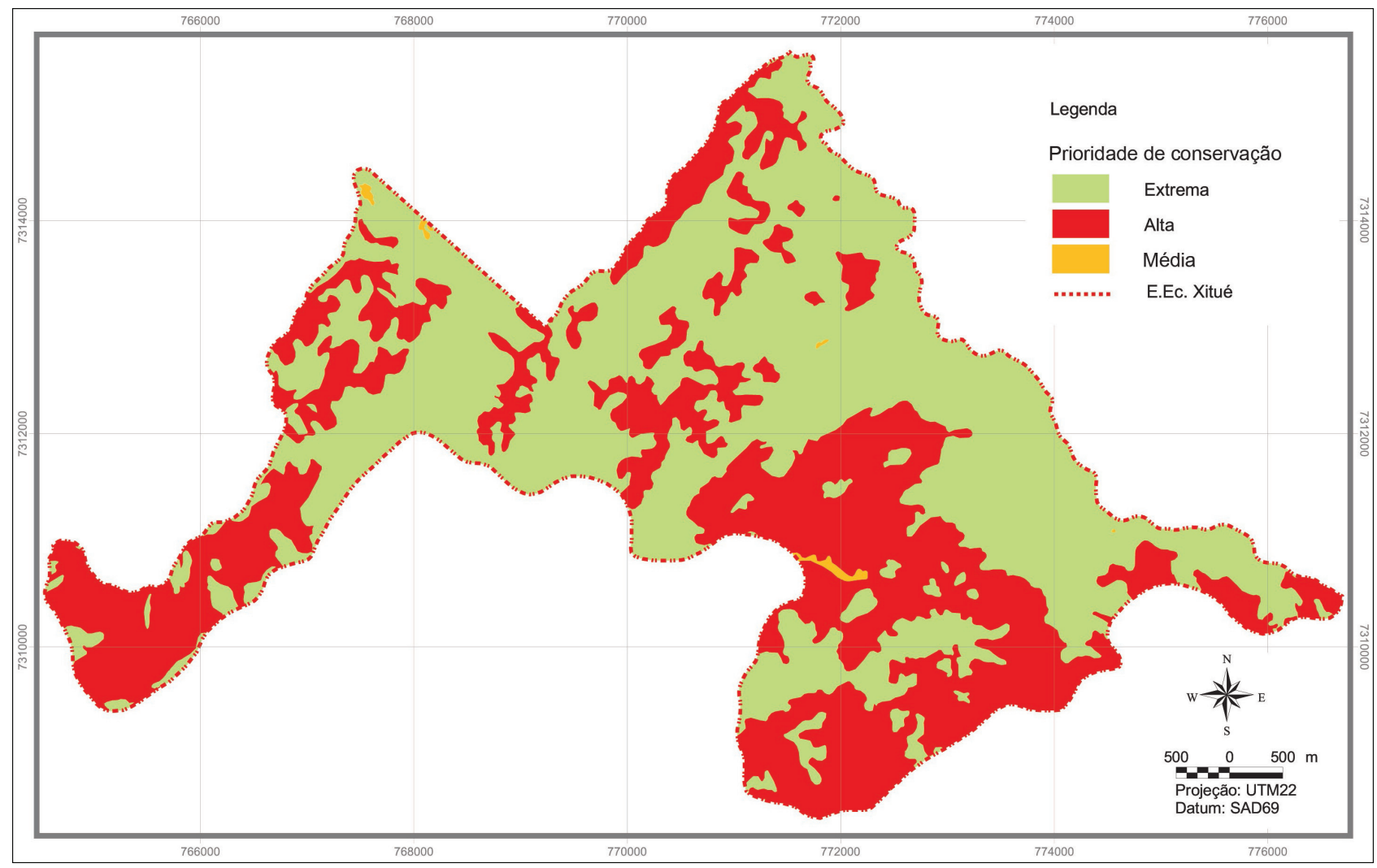

Figura 3. Áreas prioritárias para a conservação na Estação Ecológica de Xitué, Ribeirão Grande-SP.

Figure 3. Priority areas for conservation at the Xitué Ecological Station, municipality of Ribeirão Grande, São Paulo state, Brazil.

As áreas cobertas por Floresta Ombrófila Densa Alto-Montana e Aluvial estão restritas a pequenas porções na $\mathrm{EEcX}$. A distribuição restrita, aliada à especificidade da flora nessas formações vegetais, determinou o status prioritário de conservação. Por sua vez, a Floresta Ombrófila Densa Montana ocupa áreas maiores. Essas florestas apresentam porte variável, mas compartilham espécies vegetais que ocupam de forma diferenciada o espaço vertical (estratificação de diferentes formas de vida) e horizontal (mosaico de diferentes estádios sucessionais). A heterogeneidade ambiental condicionada por topografia, litologia, orientação da vertente (sul ou norte), fatores edáficos e microclimáticos associados determina a ocupação diferenciada do espaço pelas espécies em escala local e de paisagem. Essa heterogeneidade resulta em complexidade estrutural da vegetação, contribuindo para a elevada diversidade alfa e beta, observada nas florestas tropicais (Wright, 2002; Leigh Junior et al., 2004). Assim, a complexidade estrutural verificada nas áreas bem conservadas de Floresta Ombrófila Densa Montana não apenas sugere a ocorrência de elevada riqueza de espécies, mas também atesta o bom funcionamento de mecanismos ecológicos responsáveis pela origem e pela manutenção da diversidade em florestas tropicais, justificando o status prioritário de conservação atribuído a essa floresta na EEcX. 
As áreas de Floresta Ombrófila Aberta com Bambus e as áreas de Vegetação secundária foram consideradas de média prioridade de conservação, uma vez que a estrutura da vegetação encontra-se mais alterada e com menor riqueza de espécies.

Foram consideradas prioritárias para o desenvolvimento de pesquisas, as áreas de Floresta Ombrófila Densa Alto-Montana, Floresta Ombrófila Densa Montana e Floresta Ombrófila Densa Aluvial. Essa classificação se justifica pela necessidade de conhecimento da estrutura, da composição de espécies e do funcionamento de formações com pequena extensão, sujeitas a condições ambientais peculiares e compostas por espécies com alta especificidade de habitat. Esse conhecimento pode ajudar a elucidar questões centrais em ecologia, tais como a maneira como as espécies se organizam no espaço e no tempo, e os mecanismos responsáveis pela origem e pela manutenção da diversidade vegetal. Especialmente na Floresta Ombrófila Densa Alto-Montana e na Floresta Ombrófila Densa Aluvial, as condições ambientais são mais restritivas (como solo rochoso, incidência de ventos e neblina constante na Floresta Alto-Montana, e solo frequentemente encharcado na Floresta Aluvial) e constituem um filtro sobre o conjunto de espécies capazes de se estabelecer.

De acordo com os critérios utilizados, a Floresta Ombrófila Aberta com Bambus não foi considerada prioritária para pesquisa, dada a grande extensão territorial abrangida e o intenso regime de perturbação. Do ponto de vista da vegetação, trata-se de um sistema mais simples, marcado por relações competitivas bastante hierarquizadas em que, por meio de interferência direta e indireta, as espécies de bambu dominam as espécies arbóreas, impedindo o desenvolvimento de uma fisionomia florestal com a complexidade característica das florestas tropicais e subtropicais. Contudo, isso não significa que o desenvolvimento de pesquisas não seja relevante nessa formação. É essencial que se realizem estudos para avaliar o impacto da presença dessas espécies sobre as demais formas de vida da comunidade, a fim de investigar se a ocupação pelos bambus faz parte do ciclo natural da vegetação. Somente estudos de longo prazo permitirão acompanhar a trajetória dos bambus, registrar os efeitos sobre a dinâmica da comunidade, avaliar o potencial de autorrecuperação dessas áreas e definir estratégias de intervenção, se for o caso. A análise quantitativa de séries temporais de fotografias aéreas também é uma importante ferramenta para realizar essa avaliação e estimar as probabilidades de transição entre as categorias sucessionais, fornecendo subsídios para a definição de medidas de manejo.

\subsection{Zoneamento}

O zoneamento da EEcX foi realizado com base no mapa das áreas prioritárias para conservação. Duas das classes definidas pelo Roteiro Metodológico do IBAMA para Estações Ecológicas (Galante et al., 2002) foram estabelecidas: zona primitiva e zona de recuperação (Figura 4).

$\mathrm{Na}$ zona primitiva, foram incluídas as áreas mais bem preservadas de Floresta Ombrófila Densa Montana (Ma), além das fitofisionomias pouco representadas na EEcX, como a Floresta Ombrófila Densa Aluvial $(\mathrm{MaA})$, a Floresta Ombrófila Densa Alto-Montana $(\mathrm{MmA})$ e as áreas de Floresta Ombrófila Densa Montana (Mmd) situadas nos topos de morro, acima dos $900 \mathrm{~m}$ de altitude. Essa zona compreende uma área de 1.732,45 ha, correspondendo a 58,4\% da área da Estação.

A zona de recuperação foi designada para as áreas de Floresta Ombrófila Aberta com Bambus. Em decorrência do pouco conhecimento sobre a dinâmica dessa formação, recomenda-se especial atenção a essas áreas. Nesse caso, o termo "recuperação" não implica necessariamente atividades de intervenção, podendo ser conduzida apenas com a proteção e o monitoramento. As áreas em estádios iniciais de sucessão, que apresentam histórico de uso da terra (Vs2) ou que se encontram ocupadas apenas por plantas rasteiras e ruderais (Vs3), também foram incluídas nessa categoria. A zona de recuperação possui 1.232,74 ha, o que equivale a 41,6\% da EEcX.

Outra zona possível para Estações Ecológicas, segundo o mesmo roteiro, é a zona intangível, que não permite qualquer atividade humana e deve ser destinada à proteção integral dos ecossistemas. No entanto, considerando-se a total ausência de pesquisas realizadas na EEcX, optou-se por não designar nenhuma porção da área para essa zona até que se tenha um melhor conhecimento sobre suas fitofisionomias e sobre a riqueza 


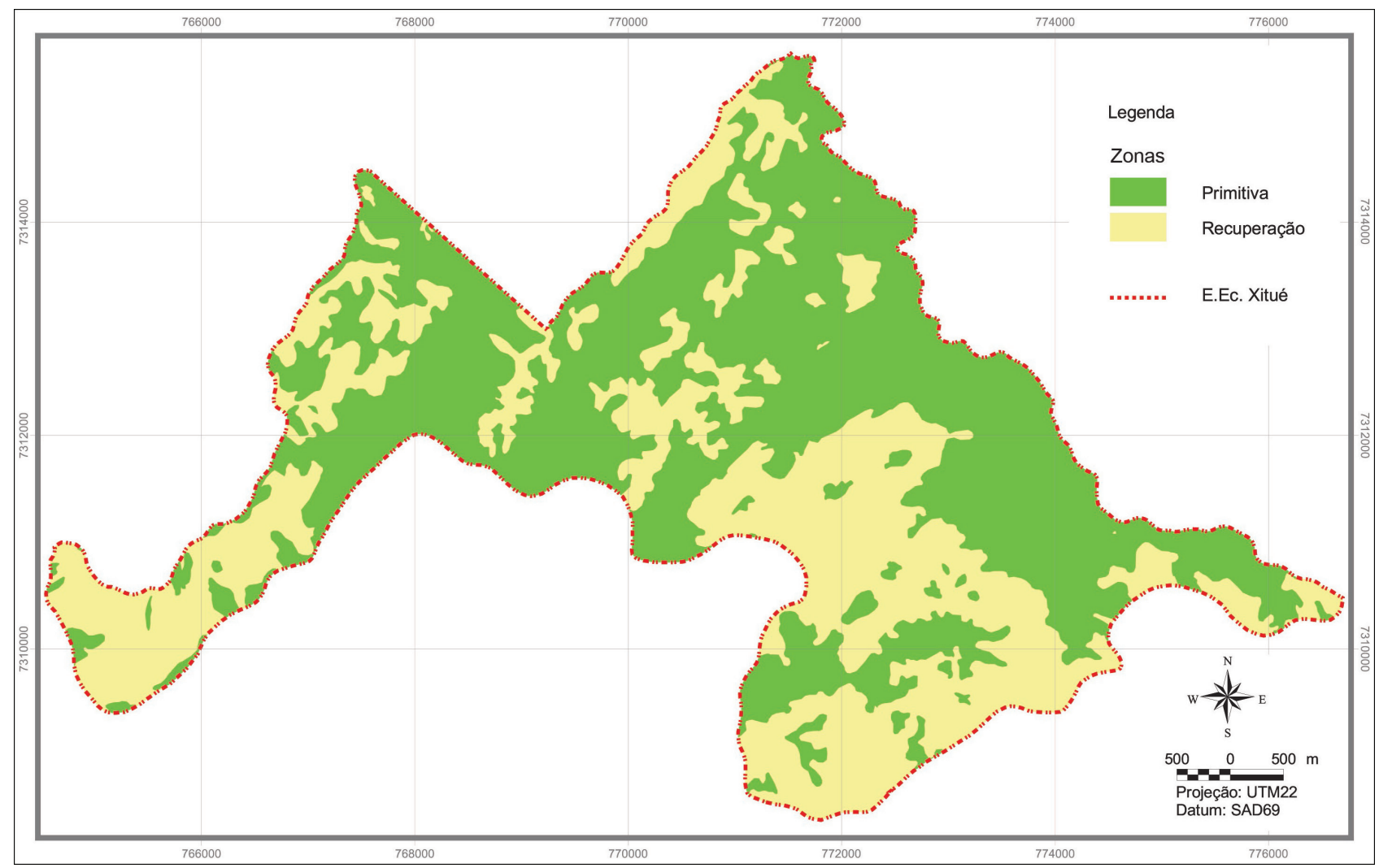

Figura 4. Zoneamento da Estação Ecológica de Xitué, Ribeirão Grande-SP.

Figure 4. Zonation of the Xitué Ecological Station, municipality of Ribeirão Grande, São Paulo state, Brazil.

de espécies. Tendo em vista que o Plano de Manejo é dinâmico e deve ser revisado a cada cinco anos, esperase que, nesse período, o conhecimento acumulado sobre a Estação já permita definir com melhor clareza quais seriam as áreas adequadas para compor essa zona.

\subsection{Importância da EEcX para a conservação da biodiversidade da Floresta Atlântica}

Estimativas do número de fanerógamas descritas mundialmente indicam a existência de mais de 350.000 espécies de plantas (The Plant List, 2013). Para o Brasil, estima-se algo em torno de 40.000 a 45.000 espécies, ou seja, $18 \%$ do total das espécies deste grupo podem ser encontradas em território nacional (Lewinsohn e Prado, 2004).

A riqueza da Floresta Atlântica no sentido amplo (lato sensu), compilada por Stehmann et al. (2009), resultou em 15.782 espécies de plantas vasculares, distribuídas em 2.257 gêneros e 348 famílias, o que corresponde a cerca de $5 \%$ da flora mundial. A taxa de endemismo obtida foi de $48 \%$, ou seja, quase metade de toda a diversidade de plantas vasculares encontradas na Floresta Atlântica é exclusiva dessa região.

Em São Paulo, o projeto "Flora Fanerogâmica do Estado de São Paulo" já registrou a ocorrência de 180 famílias, 1.500 gêneros e 8.000 espécies, entre ervas, arbustos, árvores, epífitas e trepadeiras. Analisando-se 210 estudos realizados na Floresta Ombrófila Densa e na Floresta Estacional Semidecidual do Estado, Scudeller (2002) reuniu numa única listagem 1.479 espécies de árvores. Na região do Planalto Atlântico e da Província Costeira paulista, foram registradas 1.082 espécies arbóreas*.

*(R. R. Rodrigues, dados não publicados). 
Considerando-se que as espécies arbóreas perfazem em torno de 50\% da diversidade total encontrada em inventários florísticos realizados na Floresta Atlântica (Ivanauskas et al., 2000; Zipparro et al., 2005), conclui-se que os ecossistemas florestais da Floresta Atlântica stricto sensu no estado de São Paulo abrigam algo em torno de $0,9 \%, 5 \%$ e $27 \%$ da diversidade mundial, nacional e estadual, respectivamente (Prance, 1987). Fica evidente, portanto, a grande importância da Floresta Atlântica sensu stricto paulista para a conservação da diversidade vegetal em diferentes escalas geográficas.

A manutenção das populações de plantas em longo prazo, no entanto, requer a preservação de grandes áreas contínuas de vegetação, para que os processos ecológicos que determinam os parâmetros demográficos populacionais possam operar dentro dos limites exigidos para a manutenção de populações viáveis (Howe e Smallwood, 1982; Gentry, 1983; Silva e Tabarelli; 2000; Tabarelli e Gascon, 2005; Jesus et al., 2012).

O conhecimento sobre a vegetação é fundamental para que se possam criar novas áreas protegidas, bem como subsidiar estratégias para a efetiva manutenção daquelas já existentes. Nesse contexto, o presente estudo traz uma contribuição importante para ampliar o conhecimento científico sobre a vegetação da Floresta Atlântica paulista e para orientar tecnicamente o Plano de Manejo nas ações que atendam às finalidades de conservação e pesquisa da EEcX.

\section{AGRADECIMENTOS}

Agradecemos ao Diretor do Parque Estadual Intervales, Maurício Marinho, e à Kátia Pisciotta, pelo apoio logístico. Também agradecemos ao estagiário Adriano Peres Ribeiro, ao escalador Wlademir Corrêa e aos auxiliares José Floido, José Silva, José Vieira e Paulo Ursulino da Mota, pelo inestimável auxílio em campo.

\section{REFERÊNCIAS BIBLIOGRÁFICAS}

AMORIM, A. M. et al. Angiospermas em remanescentes de floresta Montana no sul da Bahia, Brasil. Biota Neotropica, v. 9, n. 3, p. 313-348, 2009.

ANGIOSPERM PHYLOGENY GROUP - APG. An update of the Angiosperm Phylogeny Group Classification for the orders and families of flowering plants: APG III. Botanical Journal of the Linnean Society, v. 161, p. 105-121, 2009.

ARAÚJO, M. A. R. Unidades de conservação: sua importância e sua história no Brasil. In: NEXUS (Org.) Unidades de Conservação no Brasil: o caminho da gestão para resultados. São Carlos: Rima, 2012. p. 25-50.

BAIDER, C.; TABARELLI, M.; MANTOVANI, W. O banco de sementes do solo durante a regeneração da Floresta Atlântica no sudeste do Brasil. Revista Brasileira de Biologia, v. 61, n. 1, p. 35-44, 2001.

BRASIL. Lei $\mathrm{n}^{\circ}$ 9.985, de 18 de julho de 2000. Institui o Sistema Nacional de Unidades de Conservação da Natureza e dá outras providências. Diário Oficial da União, de 19 julho de 2000. Disponível em: <http://www. planalto.gov.br/ccivil_03/leis/L9985.htm>.Acesso em: 15 mar. 2010.

BRASIL. Ministério do Meio Ambiente - MMA. Instrução normativa n ${ }^{\circ}$ 6, de 23 de setembro de 2008. Reconhece as espécies da flora brasileira ameaçadas de extinção. Disponível em: <http://www.mma.gov.br/estruturas/179/_arquivos/179_05122008033615.pdf>.Acesso em: 10 jul. 2013.

BRASIL. Ministério do Meio Ambiente - MMA. Unidades de Conservação. 2014. Disponível em: <www. mma.gov.br/areas-protegidas/unidades-de-conservacao>. Acesso em: 3 abr. 2014. 
SOUZA, F. M. et al. A vegetação da Estação Ecológica de Xitué, Ribeirão Grande-SP: subsídios para o Plano de Manejo

CARVALHO, L. M. T. Dinâmica de clareiras em uma floresta de nuvem na Serra do Ibitipoca, Minas Gerais. 1997. 54 f. Dissertação (Mestrado em Manejo Ambiental)-Universidade Federal de Lavras, Lavras, 1997. CENTRO DE PESQUISAS METEOROLÓGICAS E CLIMÁTICAS APLICADAS À AGRICULTURA - CEPAGRI. Clima dos Municípios Paulistas. Campinas. Disponível em: $<$ http://www.cpa.unicamp.br/outras-informacoes/clima_muni_488.html >. Acesso em: 1 set. 2014.

CIELO-FILHO, R. et al. Ampliando a densidade de coletas botânicas na região da bacia hidrográfica do Alto Paranapanema: caracterização florística da Floresta Estadual e da Estação Ecológica de Paranapanema. Biota Neotropica, v. 9, n. 3, p. 255-273, 2009.

EITEN, G. A vegetação do Estado de São Paulo. Boletim do Instituto de Botânica, v. 7, p. 1-147, 1970.

FRANCO, G. A. D. C. et al. Importância dos remanescentes florestais de Embu (São Paulo) para a conservação da flora regional. Biota Neotropica, v. 7, n. 3, 2007. Disponível em: <http://www.biotaneotropica.org.br/v7n3/ pt/abstract?article+bn02507032007>. Acesso em: 23 out. 2008.

FUNDAÇÃO FLORESTAL. Plano de Manejo do Parque Estadual Intervales - Diagnóstico e Avaliação. Vegetação. São Paulo, 2008. p. 337-396. Disponível em: <http://fflorestal.sp.gov.br/planos-de-manejo/planos-de-manejo-planos-concluidos/>. Acesso em: 15 mar. 2014.

FUnDAÇÃo FlORESTAL. Plano de Manejo do Parque Estadual do Jaraguá. São Paulo, 2010. Disponível em: <http://fflorestal.sp.gov.br/planos-de-manejo/planos-de-manejo-planos-concluidos $>$. Acesso em: 16 jan. 2011.

GAlAnte, M. L. V. et al. Roteiro Metodológico de Planejamento: Parque Nacional, Reserva Biológica, Estação Ecológica. Brasília: Edições IBAMA, 2002. 136 p.

GENTRY, A. H. Dispersal ecology and diversity in neotropical forest communities. Sonderbände Naturwissenschaftlichen Vereins im Hamburg, v. 7, p. 313-314, 1983.

GUILHERME, F. A. G. et al. Effects of flooding regimes and woody bamboos on tree community dynamics in a section of tropical semideciduous forest in South-Eastern Brazil. Plant Ecology, v. 174, n. 1, p. 19-36, 2004.

HOWE, H. F.; SMALLWOOD, J. Ecology of seed dispersal. Annual Reviews of Ecology and Systematics, v. 13, p. 201-208, 1982.

HUBBELL, S. P. A unified theory of biogeography and relative species abundance and its application to tropical rain forests and coral reefs. Coral Reefs, v. 16, p. S9-S21, 1997. Supplement.

HUBBELL, S. P. The unified neutral theory of biodiversity and biogeography. Princeton: Princeton University Press, 2001. 375 p.

INSTITUTO BRASILEIRO DE GEOGRAFIA E ESTATÍSTICA - IBGE. Manual técnico da vegetação brasileira: sistema fitogeográfico, inventário das formações vegetais e campestres, técnicas de manejo de coleções botânicas, procedimentos para mapeamentos. 2. ed. Rio de Janeiro, 2012. 271 p. (Manuais Técnicos em Geociências, 1).

INSTITUTO FLORESTAL. Plano de Manejo do Parque Estadual Carlos Botelho. São Paulo, 2008. Disponível em: <http://fflorestal.sp.gov.br/planos-de-manejo/planos-de-manejo-planos-concluidos/>. Acesso em: 10 jan. 2011. 
INTERNATIONAL UNION FOR CONSERVATION OF NATURE - IUCN. The IUCN red list of threatened species. Version 2013.1. Switzerland, 2013. Disponível em: $<$ http://www.iucnredlist.org $>$. Acesso em 04 jul. 2013.

IVANAUSKAS, N. M.; MONTEIRO, R.; RODRIGUES, R. R. Similaridade florística entre áreas de Floresta Atlântica no Estado de São Paulo. Brazilian Journal of Ecology, v. 1, n. 4, p. 71-81, 2000.

JESUS, F. M. et al. The importance of landscape structure for seed dispersal in rain forest fragments. Journal of Vegetation Science, v. 23, p. 1126-1136, 2012.

KEEL, S.; SAYRE, R.; SEDAGHATKISH, G. Levantamentos da vegetação e espécies de plantas. In: SAYRE, R. et al. (Ed.). Natureza em foco: avaliação ecológica rápida. Arlington: The Nature Conservancy, 2003. p. 79-90.

LEIGH JUNIOR, E. G. et al. Why do some tropical forests have so many species of trees? Biotropica, v. 36, n. 4, p. 447-473, 2004.

LEWINSOHN, T. M.; PRADO, P. I. Biodiversidade brasileira: síntese do estado atual de conhecimento. São Paulo: Contexto, 2004. 176 p.

LIMA, R. A. F et al. Bamboo overabundance alters forest structure and dynamics in the Atlantic Forest hotspot. Biological Conservation, v. 147, p. 32-39, 2012.

LISTA DE ESPÉCIES DA FLORA DO BRASIL. Jardim Botânico do Rio de Janeiro. Disponível em: < http:// floradobrasil.jbrj.gov.br/>. Acesso em: 04 Set. 2013

LORENZI, H. et al. Palmeiras no Brasil: nativas e exóticas. Nova Odessa: Editora Plantarum, 1996. 303 p.

LUEDER, D. R. Serial photographic interpretation, principles and applications. New York: MacGraw-Hill, 1959. $462 \mathrm{p}$.

MAGURRAN, A. E. Measuring biological diversity. Malden: Blackwell Publishing, 2004. 256 p.

MAMEDE, M. C. H. et al. Livro vermelho das espécies vegetais ameaçadas do Estado de São Paulo. São Paulo: Instituto de Botânica, 2007. 165 p.

OLIVEIRA, J. B. et al. Mapa pedológico do Estado de São Paulo: legenda expandida. Campinas: Instituto Agronômico/EMBRAPA Solos, 1999. 64 p. v. 1.

OLIVEIRA-FILHO, A. T. et al. Effect of flooding regime and understorey bamboos on the physiognomy and tree species composition of a tropical semideciduous forest in southeastern Brazil. Vegetatio, v. 113, n. 2, p. 99-124, 1994.

PRANCE, G. T. Biogeography of neotropical plants. In: WHITMORE, T. C.; PRANCE, G. T. (Ed.). Biogeography and quaternary history in tropical America. Oxford: Clarendon Press, 1987. p. 46-65.

RIBEIRO, M. C. et al. The Brazilian Atlantic Forest: how much is left and how is the remaining forest distributed? Implications for conservation. Biological Conservation, v. 142, n. 6, p. 1141-1153, 2009.

ROSSETTO, E. F. S.; VIEIRA, A. O. S. Vascular Flora of the Mata dos Godoy State Park, Londrina, Paraná, Brazil. Check List, v. 9, n. 5, p. 1020-1034, 2013.

ROTHER, D. C.; RODRIGUES, R. R.; PIZO, M. A. Effects of bamboo stands on seed rain and seed limitation in a rainforest. Forest Ecology and Management, v. 257, n. 3, p. 885-892, 2009. 
SAITER, F. Z. et al. Tree changes in a mature rainforest with high diversity and endemism on the Brazilian coast. Biodiversity \& Conservation v. 20, n. 9, p. 1921-1949, 2011.

SÃO PAULO. Parque Estadual de Intervales. Plano de gestão - Fase I. São Paulo: Fundação Florestal, 1998. $231 \mathrm{p}$.

SCUDELleR, V. V. Análise fitogeográfica da Mata Atlântica - Brasil. 2002. 204 f. Tese (Doutorado em Biologia Vegetal)-Universidade Estadual de Campinas, Campinas.

SILVA, J. M. C.; TABARELLI, M. Tree species impoverishment and the future flora of the Atlantic forest of the Northeast Brazil. Nature, v. 404, n. 6773, p. 72-74, 2000.

SPURR, S. H. Photogrammetry and photo-interpretation. New York: Ronald Press, 1960. 427 p.

StehmanN, J. R. et al. (Ed.). Plantas da Floresta Atlântica. Rio de Janeiro: Jardim Botânico do Rio de Janeiro, 2009. $516 \mathrm{p}$.

TABANEZ, A. A. J.; VIANA, V. M. Patch structure within Brazilian Atlantic forests fragments and implications for conservation. Biotropica, v. 32, n. 4b, p. 925-933, 2000.

TABARELLI, M.; GASCON, C. Lessons from fragmentation research: improving management and policy guidelines for biodiversity conservation. Conservation Biology, v. 19, n. 3, p. 734-739, 2005.

THE PLANT LIST. Versão 1.1. Disponível em: <http://www.theplantlist.org/>. Acesso em: 10 fev. 2013.

THOMAS, W. W. et al. Plant endemism in two forests in southern Bahia, Brazil. Biodiversity Conservation, v. 7, n. 3, p. 311-322, 1998.

WIDMER, Y. Pattern and performance of understory bamboos (Chusquea spp.) under different canopy closures in old-growth oak forest in Costa Rica. Biotropica, v. 30, n. 3, p. 400-415, 1998.

WRIGHT, S. J. Plant diversity in tropical forests: a review of mechanisms of species coexistence. Oecologia, v. 130, n. 1, p. 1-14, 2002.

XAVIER, A. F.; BOLZANI, B. M.; JORDÃO, S. Unidades de conservação da natureza no estado de São Paulo. In: RODRIGUES, R. R.; BONONI, V. L. R (Org.). Diretrizes para a conservação e restauração da biodiversidade no estado de São Paulo. São Paulo: Instituto de Botânica, 2008. p. 24-24.

ZILLER, S. R. Plantas exóticas invasoras: a ameaça da contaminação biológica. Ciência Hoje, v. 30, n. 178, p. 77-79, 2001.

ZIPPARRO, V. B. et al. Levantamento florístico de Floresta Atlântica no sul do estado de São Paulo, Parque Estadual de Intervales, Base Saibadela. Biota Neotropica, v. 5, n. 1, p. 147-170, 2005. 
Anexo 1. Caracterização dos trechos de vegetação na Estação Ecológica de Xitué. 0 - ausente; 1 - pouco; 2 - muito. Appendix 1. Characterization of the trail segments at the Xitué Ecological Station. 0 - absent; 1 - scarce; 2 - frequent.

\begin{tabular}{|c|c|c|c|c|c|c|c|c|}
\hline \multirow{2}{*}{ Variável / Trecho } & \multicolumn{5}{|c|}{ Trilha de Xitué } & \multicolumn{3}{|c|}{ Trilha do Rio das Almas } \\
\hline & X-I & $\mathrm{X}-\mathrm{II}$ & X-III & X-IV & $\mathrm{X}-\mathrm{V}$ & RA-I & RA-II & RA-III \\
\hline \multicolumn{9}{|l|}{ Topografia } \\
\hline Topo de Morro & 0 & 0 & 0 & 0 & 0 & 0 & 0 & 0 \\
\hline Encosta & 0 & 0 & 0 & 0 & 0 & 0 & 0 & 0 \\
\hline Fundo de Vale & 1 & 1 & 1 & 1 & 1 & 1 & 1 & 1 \\
\hline Planície & 0 & 0 & 0 & 0 & 0 & 0 & 0 & 0 \\
\hline \multicolumn{9}{|l|}{ Solo } \\
\hline Arenoso & 0 & 0 & 0 & 0 & 0 & 0 & 0 & 0 \\
\hline Argiloso & 1 & 1 & 1 & 1 & 1 & 1 & 1 & 1 \\
\hline Hidromórfico & 0 & 0 & 0 & 0 & 0 & 0 & 0 & 0 \\
\hline Litossolo & 0 & 0 & 0 & 0 & 0 & 0 & 0 & 0 \\
\hline \multicolumn{9}{|l|}{ Vizinhança } \\
\hline Pinus & 0 & 0 & 0 & 0 & 0 & 0 & 0 & 0 \\
\hline Eucalipto & 0 & 0 & 0 & 0 & 0 & 0 & 0 & 0 \\
\hline Agricultura & 0 & 0 & 0 & 0 & 0 & 0 & 0 & 0 \\
\hline \multicolumn{9}{|l|}{ Vizinhança } \\
\hline Pasto & 0 & 0 & 0 & 0 & 0 & 0 & 0 & 0 \\
\hline Habitação & 0 & 0 & 0 & 0 & 0 & 0 & 0 & 0 \\
\hline Mineração & 0 & 0 & 0 & 0 & 0 & 0 & 0 & 0 \\
\hline Rio e/ou Lago & 0 & 1 & 0 & 1 & 1 & 1 & 1 & 1 \\
\hline Estrada & 0 & 0 & 0 & 0 & 0 & 0 & 0 & 0 \\
\hline Rede elétrica & 0 & 0 & 0 & 0 & 0 & 0 & 0 & 0 \\
\hline Oleodutos & 0 & 0 & 0 & 0 & 0 & 0 & 0 & 0 \\
\hline Outros & 0 & 0 & 0 & 0 & 0 & 0 & 0 & 0 \\
\hline
\end{tabular}

Fatores de perturbação

\begin{tabular}{|c|c|c|c|c|c|c|c|}
\hline Animais exóticos & 0 & 0 & 0 & 0 & 0 & 0 & 0 \\
\hline Fogo & 0 & 0 & 0 & 0 & 0 & 0 & 0 \\
\hline Erosão & 0 & 0 & 0 & 0 & 0 & 0 & 0 \\
\hline Corte Seletivo & 0 & 0 & 0 & 0 & 0 & 0 & 0 \\
\hline Caça & 0 & 0 & 0 & 0 & 0 & 1 & 1 \\
\hline Lixo & 0 & 0 & 0 & 0 & 0 & 0 & 0 \\
\hline Outros & 0 & 0 & 0 & 0 & 0 & 0 & 0 \\
\hline
\end{tabular}

Conservação da trilha

\begin{tabular}{llllllllll} 
Excelente & 0 & 0 & 0 & 0 & 0 & 0 & 0 & 0 \\
Bom & 1 & 1 & 1 & 1 & 1 & 0 & 0 & 0 \\
Regular & 0 & 0 & 0 & 0 & 0 & 1 & 1 & 1 \\
Ruim & 0 & 0 & 0 & 0 & 0 & 0 & 0 & 0 \\
\hline
\end{tabular}


SOUZA, F. M. et al. A vegetação da Estação Ecológica de Xitué, Ribeirão Grande-SP: subsídios para o Plano de Manejo

Anexo 1. Continuação...

Appendix 1. Continued...

\begin{tabular}{|c|c|c|c|c|c|c|c|c|}
\hline \multirow{2}{*}{ Variável / Trecho } & \multicolumn{5}{|c|}{ Trilha de Xitué } & \multicolumn{3}{|c|}{ Trilha do Rio das Almas } \\
\hline & X-I & X-II & X-III & X-IV & $\mathrm{X}-\mathrm{V}$ & RA-I & RA-II & RA-III \\
\hline \multicolumn{9}{|l|}{ Fitofisionomia } \\
\hline FOD - Alto-Montana & 0 & 0 & 0 & 0 & 0 & 0 & 0 & 0 \\
\hline FOD - Montana & 1 & 1 & 1 & 1 & 1 & 1 & 1 & 1 \\
\hline FOD - Submontana & 0 & 0 & 0 & 0 & 0 & 0 & 0 & 0 \\
\hline FOD - Terras Baixas & 0 & 0 & 0 & 0 & 0 & 0 & 0 & 0 \\
\hline FOD - Aluvial & 0 & 0 & 0 & 0 & 0 & 0 & 0 & 0 \\
\hline Restinga & 0 & 0 & 0 & 0 & 0 & 0 & 0 & 0 \\
\hline Campo & 0 & 0 & 0 & 0 & 0 & 0 & 0 & 0 \\
\hline Número de estratos & 1 & 4 & 2 & 4 & 1 & 3 & 4 & 3 \\
\hline \multicolumn{9}{|l|}{ Altura das árvores } \\
\hline Emergentes & 0 & 18 & 0 & 20 & 0 & 0 & 20 & 0 \\
\hline \multicolumn{9}{|l|}{ Altura das árvores } \\
\hline Dossel & 12 & 15 & 0 & 15 & 0 & 15 & 16 & 15 \\
\hline Subdossel & 0 & 10 & 7 & 11 & 0 & 7 & 8 & 7 \\
\hline Subosque & 0 & 3 & 3 & 4 & 3 & 3,5 & 4 & 3,5 \\
\hline
\end{tabular}

Diâmetro das árvores do dossel

Gigantes (DAP > $100 \mathrm{~cm}$ )

Grandes $(20<$ DAP $\leq 100 \mathrm{~cm})$

Médias (DAP $\leq 20 \mathrm{~cm})$

Subosque

Denso (visão alcança até $5 \mathrm{~m}$ )

Médio (visão alcança de 5 a

$15 \mathrm{~m})$

Ralo (visão alcança acima de $15 \mathrm{~m}$ )

Espécies indicadoras

Macroepífitas

Trepadeiras não agressivas

Ervas terrestres

$\begin{array}{llllllll}0 & 0 & 0 & 0 & 0 & 0 & 1 & 0 \\ 1 & 2 & 1 & 2 & 1 & 2 & 1 & 2 \\ 0 & 1 & 0 & 1 & 1 & 1 & 1 & 1\end{array}$

Espécies indicadoras

Bambus

Taquaras

Trepadeiras agressivas

Exóticas

$\begin{array}{llllllll}1 & 0 & 1 & 0 & 1 & 0 & 0 & 0 \\ 0 & 0 & 0 & 0 & 0 & 1 & 0 & 1 \\ 0 & 1 & 0 & 1 & 0 & 0 & 1 & 0\end{array}$

Estádio sucessional

Madura

$\begin{array}{llllllll}0 & 2 & 1 & 2 & 1 & 1 & 2 & 1 \\ 0 & 1 & 0 & 1 & 0 & 1 & 1 & 1 \\ 2 & 2 & 1 & 1 & 1 & 1 & 2 & 1\end{array}$

21

2001

$2 \quad 0 \quad 1$

$0 \quad 0 \quad 0$

$\begin{array}{lllll}0 & 2 & 1 & 1 & 1 \\ 1 & 1 & 2 & 0 & 2 \\ 0 & 1 & 1 & 1 & 1 \\ 0 & 0 & 0 & 0 & 0\end{array}$


SOUZA, F. M. et al. A vegetação da Estação Ecológica de Xitué, Ribeirão Grande-SP: subsídios para o Plano de Manejo

Anexo 1. Continuação...

Appendix 1. Continued...

\begin{tabular}{lcccccccc}
\hline \multirow{2}{*}{ Variável / Trecho } & \multicolumn{3}{c}{ Trilha de Xitué } & \multicolumn{3}{c}{ Trilha do Rio das Almas } \\
\cline { 2 - 9 } & X-I & X-II & X-III & X-IV & X-V & RA-I & RA-II & RA-III \\
\hline Intermediária & 0 & 1 & 0 & 1 & 0 & 0 & 1 & 0 \\
Secundária & 1 & 0 & 1 & 0 & 1 & 1 & 0 & 1 \\
\hline
\end{tabular}

